Universidade de São Paulo

Escola Superior de Agricultura "Luiz de Queiroz"

Modelos preditivos de seleção genômica para a composição do óleo de soja utilizando diferentes métodos de genotipagem

\title{
Melina Prado
}

Dissertação apresentada para obtenção do título de Mestra em Ciências. Área de concentração: Genética e Melhoramento de Plantas

Piracicaba 


\section{Melina Prado}

Engenheira Biotecnológica

Modelos preditivos de seleção genômica para composição do óleo de soja utilizando diferentes métodos de genotipagem

versão revisada de acordo com a Resolução CoPGr 6018 de 2011

\section{Orientador:}

Prof. Dr. JOSÉ BALDIN PINHEIRO

Dissertação apresentada para obtenção do título de Mestra em Ciências. Área de concentração: Genética e Melhoramento de Plantas 


\section{Dados Internacionais de Catalogação na Publicação DIVISÃO DE BIBLIOTECA - DIBD/ESALQ/USP}

\section{Prado, Melina}

Modelos preditivos de seleção genômica para composição do óleo de soja utilizando diferentes métodos de genotipagem / Melina Prado. - - versão revisada de acordo com a resolução CoPGr 6018 de 2011. - - Piracicaba, 2021.

$55 \mathrm{p}$.

Dissertação (Mestrado) - - USP / Escola Superior de Agricultura "Luiz de Queiroz".

1. Seleção genômica 2. Genotipagem 3. Ácidos graxos 4. Glycine max I. Título 
DEDICATÓRIA

"Com amor, dedico meu trabalho a Marco Antônio do Prado, Rosimeire Teixeira Prado, Bruno Teixeira Prado e Gustavo Husein." 
EPÍGRAFE

“Equipado com seus cinco sentidos, o homem explora o universo ao seu redor e chama suas aventuras de ciência." Edwin Powell Hubble 


\section{SUMÁRIO}

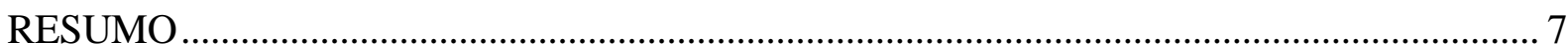

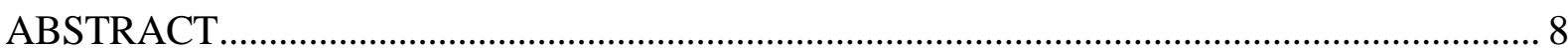

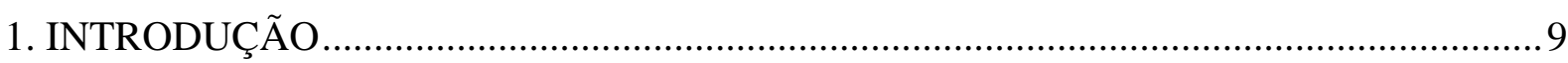

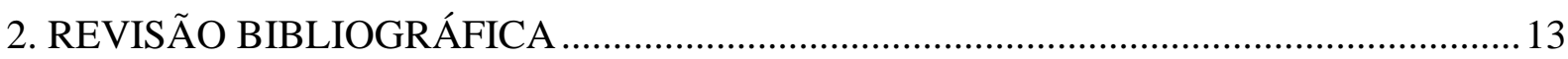

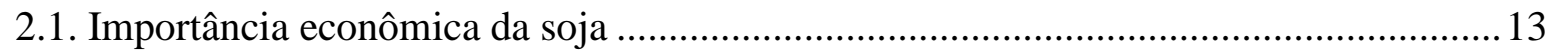

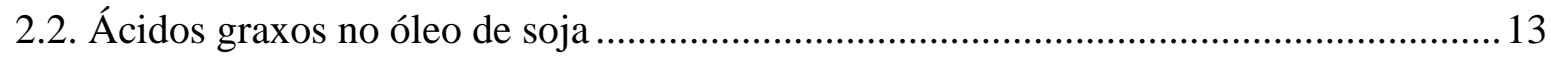

2.3. Melhoramento para a composição do óleo de soja................................................... 14

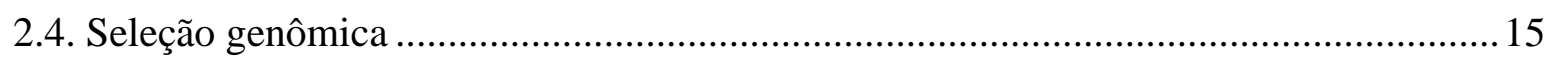

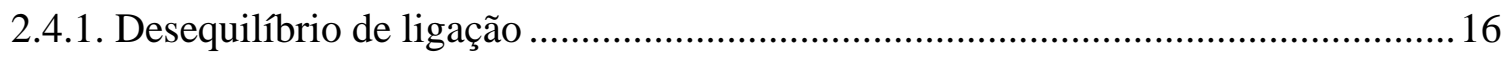

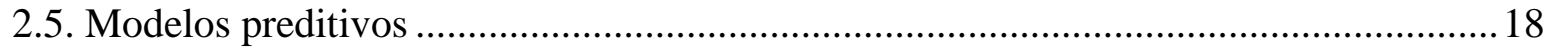

2.5.1. Modelo GBLUP para estimação dos efeitos dos marcadores.................................20

2.5.2. Modelo BayesB para estimação dos efeitos dos marcadores ..................................2 20

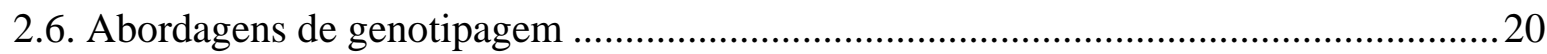

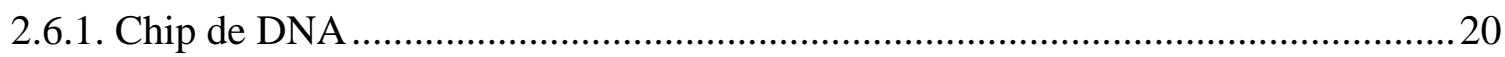

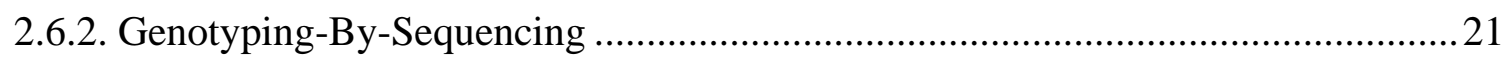

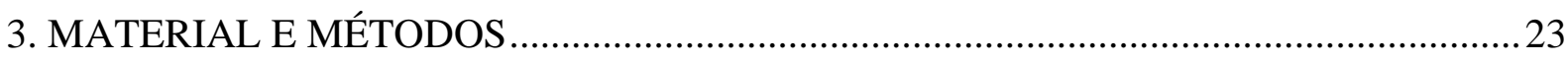

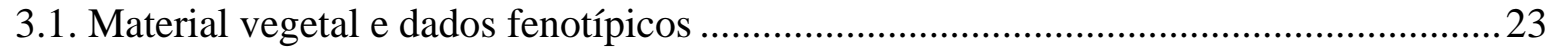

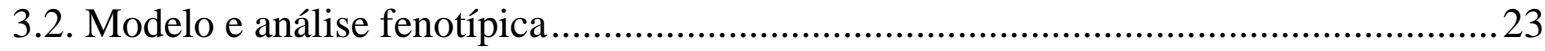

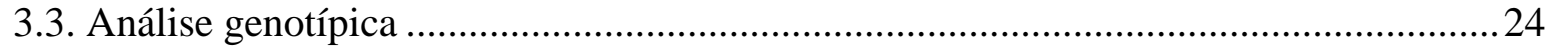

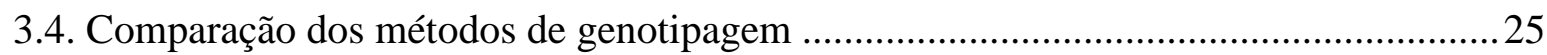

3.4.1. Coeficientes de Correlação de Pearson ................................................................. 25

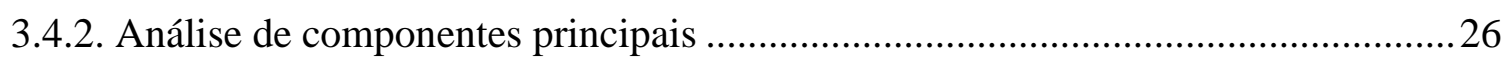

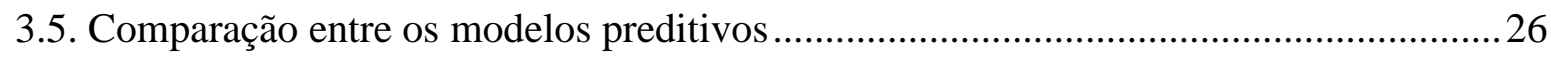

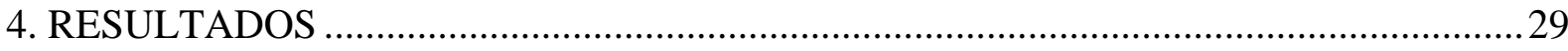

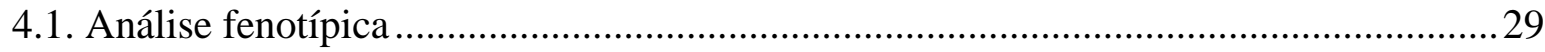

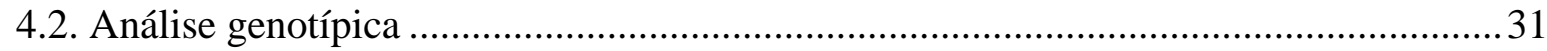

4.2.1. Coeficientes de Correlação de Pearson ........................................................................ 31

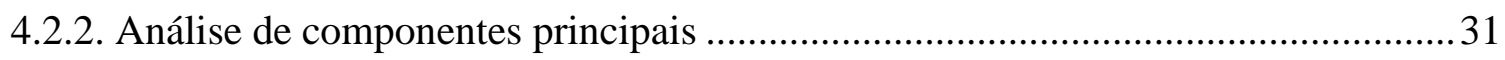

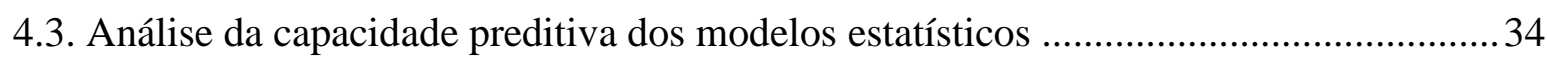

4.3.1. Erro Médio Quadrático de Predição ....................................................................... 34

4.3.2. Análise da acurácia preditiva dos modelos ........................................................... 35

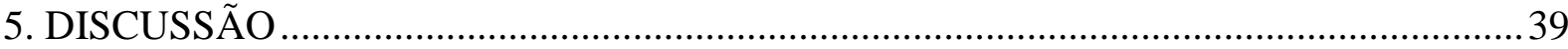




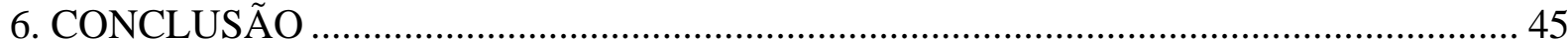

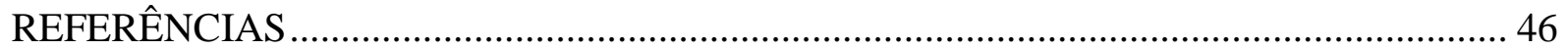

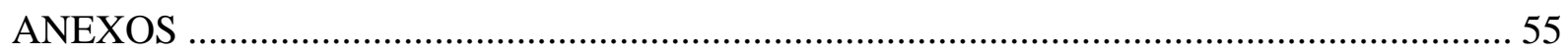


RESUMO

Modelos preditivos de seleção genômica para composição do óleo de soja utilizando

diferentes métodos de genotipagem

O óleo de soja se destina a vários objetivos, como óleo de cozinha, biodiesel, entre outros. A composição do óleo em relação aos ácidos graxos modifica o tempo de prateleira, a palatabilidade e o quanto esse óleo é saudável ou não para dieta humana. A seleção genômica utiliza de maneira conjunta o efeito de todos os marcadores ao mesmo tempo e relaciona esses efeitos aos fenótipos observados, aumentando o ganho genético no tempo. O objetivo do trabalho foi avaliar modelos de seleção genômica, utilizando duas formas de genotipagem, para a composição de ácidos graxos no óleo de soja, sendo esses os ácidos oleico, linoleico, linolênico, palmítico, esteárico e o óleo total. Os métodos de genotipagem que foram avaliados são o chip, ou arranjo de DNA, e o método de genotipagem por sequenciamento utilizando enzimas de restrição. Para comparar esses dois métodos o coeficiente de correlação de Pearson e uma análise de componentes principais foram calculados a partir das matrizes de parentesco geradas por esses dois métodos. A análise do coeficiente de Pearson foi utilizada para comparar dados com e sem filtragem e imputação de SNPs. As duas abordagens de genotipagem foram utilizadas nos modelos de predição, GBLUP e BayesB, a fim de comparação entre os métodos e genotipagens, e para uma avaliação da performance dessas combinações na seleção genômica para os caracteres avaliados. A população utilizada na análise era composta por dois grupos com aproximadamente $30 \%$ de cultivares e $70 \%$ de introdução de plantas. A análise de componentes principais a partir do chip de DNA separou de forma mais clara os dois grupos utilizados do que o método de genotipagem com enzimas de restrição. Os coeficientes de correlação de Pearson demonstraram que a plataforma de genotipagem por chip possui uma correlação maior entre dados filtrados e não filtrados. Isso acontece pois se trata de uma plataforma bem consolidada comercialmente com estudos nos polimorfismos mais informativos, mas que por conter um número limitado de polimorfismos a serem utilizados na análise não capta alelos raros que poderiam ser de grande utilidade a seleção. Enquanto a plataforma de genotipagem por sequenciamento pode captar esses alelos raros, mas possui menor confiança nos resultados e necessidade de uma análise mais robusta. De forma geral, a análise de acurácia preditiva e o erro médio quadrático de predição demonstraram que para população, espécie e caracteres avaliados o método $6 \mathrm{~K}$ e o modelo GBLUP resultaram em melhores performances, com exceção de dois caracteres, o óleo total e o ácido esteárico, pois a melhor performance foi alcançada com a genotipagem por sequenciamento. Como o óleo de soja é utilizado para diversas funções e os perfis de ácido graxo são diferentes para cada objetivo, o trabalho constitui um importante estudo e direcionamento para o melhoramento da composição do óleo de soja.

Palavras-chave: Seleção genômica, Genotipagem, Ácidos graxos, Glycine max 


\begin{abstract}
Genomic selection prediction models for soybean oil composition using different types of genotyping methods
\end{abstract}

Soybean oil is used for several purposes, such as cooking oil, biodiesel and others. The composition of the oil in relation to fatty acids changes shelf life, palatability and how healthy or unhealthy this oil is for the human diet. Genomic selection uses together the effect of all markers at the same time and compare these effects to the observed phenotypes, increasing the genetic gain over time. The objective of the work was to evaluate models of genomic selection, using two forms of genotyping, for the composition of fatty acids, which are the oleic, linoleic, linolenic, palmitic and stearic acids in soybean oil and the total oil content. The genotyping methods that have been evaluated are DNA chip, or DNA array, and the genotyping method by sequencing using restriction enzymes. To compare these two methods, Pearson's correlation coefficient and a principal component analysis were calculated from the kinship matrices generated by these two methods. Pearson's coefficient analysis was used to compare data with and without filtering and imputation of SNPs. The two genotyping approaches were used in the prediction models, GBLUP and BayesB, in order to compare the methods and genotyping, and to evaluate the performance of these combinations in genomic selection. The population used in the analysis was composed of two groups with approximately $30 \%$ of cultivars and $70 \%$ of plant introduction. Principal component analysis from the DNA chip clearly separated the two groups used, while the restriction enzyme genotyping method did not. Pearson's correlation coefficients demonstrated that the chip genotyping platform has a greater correlation between filtered and unfiltered data. This happens because it is a well consolidated and commercial platform with studies in the most informative polymorphisms, but because of this it contains a limited number of polymorphisms to be used in the analysis and it could not capture rare alleles that could be of great use to selection. While the sequencing genotyping platform can capture these rare alleles, but it has less confidence in the results and the need for a more robust analysis. In general, the predictive accuracy analysis and the mean square error of prediction showed that for population, species and characters evaluated, the SNP array method and the GBLUP model resulted in better performances, with the exception of two characters, total oil and stearic acid. For these two traits, the best performance was achieved with genotyping-by-sequencing. As soybean oil is used for different functions and the fatty acid profiles are different for each objective, the work constitutes an important study and direction for improving the composition of soybean oil.

Keywords: Genomic selection, Genotyping, Fatty acids, Glycine max 


\section{INTRODUÇÃO}

A soja [Glycine max (L.) Merrill], da família Fabaceae (Leguminosae), é uma planta oriunda da China e introduzida no Brasil em 1882, começando a ser cultivada pelos agricultores em 1924. Nessa época seu uso se deu principalmente pela vantagem de aproveitamento da lavoura ociosa de trigo no verão. A partir de 1924 houve expansão crescente da área de cultivo e isso se deve a muitos fatores, por ser uma planta de sucessão ao trigo, fácil adaptação no Brasil e condições favoráveis de mercado (COSTA, 1996). Hoje em dia a soja representa um marco crucial no agronegócio brasileiro, sua cultura trouxe mecanização para as lavouras brasileiras, potencializou o comércio internacional, e é o produto mais exportado do Brasil, sendo responsável por um quarto do valor das exportações do agronegócio (GAZZONI; DALL'AGNOL, 2018). Embora a soja represente grande importância econômica ao país, a cultura também necessita de mudanças para uma produção mais sustentável, entre muitos outros alvos do melhoramento, como o aumento de sua produtividade, a resistência a estresses bióticos e abióticos, a mudança de sua composição química de acordo com os objetivos e o produto desejado, entre outros.

Por muitos anos o melhoramento somente utilizou a Seleção Assistida por Marcadores (MAS, do inglês Marker-Assisted Selection) para realizar o melhoramento por meio de dados provenientes do DNA. A Seleção Genômica (GS, do inglês Genomic Selection) não era amplamente utilizada no passado por necessitar de uma genotipagem densa e com custo reduzido. Como os marcadores eram restritos e de custo elevado, a técnica passou a ser uma opção quando esse cenário mudou. (RESENDE et al., 2008; MEUWISSEN; HAYES; GODDARD, 2001).

A GS aumenta o ganho genético por unidade de tempo nos programas de melhoramento e utiliza as informações genômicas de maneira densa. Na GS um modelo estatístico é utilizado e ajustado para a população que irá passar pela seleção. São utilizadas três populações no processo todo, a população de treinamento do modelo, a população de validação desse mesmo modelo e a população de seleção. Após a construção, ajuste e validação do modelo estatístico, este poderá ser utilizado em uma população com genotipagem apenas.

Há muitos modelos preditivos de seleção genômica e a escolha desse modelo depende da estrutura genômica da população e do parentesco entre os indivíduos. O modelo GBLUP é um método de estimação penalizada que parte do princípio que a variância genômica é de igual valor para todos os marcadores, isso baseia-se na ideia de que os caracteres são controlados por grande número de genes com pequenos efeitos. Já o modelo BayesB da família Bayeasiana 
considera que muitos SNPs (SNP, do inglês Single Nucleotide Polimorphism) podem ter efeitos nulos e que os caracteres considerados podem ser governados por menor número de genes, podendo alguns genes serem de maiores efeitos. Nesse modelo a distribuição dos efeitos é inferida a priori.

As plataformas de genotipagem tornaram possível o estabelecimento da GS como um método viável nos programas de seleção, na qual uma distribuição densa e ampla dos marcadores faz-se necessária para uma boa acurácia. O desenvolvimento de chips de genotipagem fez com que a obtenção das informações genômicas do indivíduo fossem extraídas com maior facilidade, precisão e velocidade. Pois estudos prévios para descoberta dos polimorfismos foram realizados em muitos organismos e assim foram encontrados SNPs que representam os polimorfismos mais informativos.

Como os chips representam polimorfismos alélicos, eles são específicos a apenas uma espécie e por isso muitos organismos ainda não possuem chips disponíveis no mercado. Quanto mais estreita a base genética de um organismo, mais provável uma alta eficiência da genotipagem por chip nas populações que serão utilizadas para a seleção. O outro lado é que, por representar os polimorfismos mais representativos de uma dada espécie, muitos SNPs raros de grande importância não são captados nesse tipo de genotipagem e isso é uma informação a ser levada em conta no momento de escolha da abordagem de genotipagem. Para espécies que possuem uma base genética ampla e poucos estudos de seu genoma, uma interessante forma de genotipagem é por sequenciamento utilizando enzimas de restrição (GIBBS; TAYLOR; TASSELL, 2009).

A partir das plataformas de NGS (NGS, do inglês Next Generation Sequencing) foi possível criar uma genotipagem por sequenciamento (Genotyping-By-Sequencing - GBS), a qual produz um número ilimitado de marcadores, podendo ter densidade e amplitude variáveis. Pois a técnica utiliza enzimas e sítios de restrição do genoma, podendo ser utilizadas enzimas de cortes raros, frequentes e intermediários, de acordo com o objetivo do estudo. Como possui uma amplitude grande de possíveis resultados, a confiança também é menor em relação aos chips bem estabelecidos do mercado. É necessária uma análise de bioinformática mais robusta, já que a abordagem pode possuir dados perdidos, alelos em que quase não se acham polimorfismos e ainda erros devido a quantidade de heterozigotos na população. Para esses problemas faz-se necessário a utilização de filtros após a genotipagem e uma imputação de SNPs.

A soja é uma espécie paleoalotetraploide que resultou de duas duplicações genômicas que aconteceram a 13 e 59 milhões de anos atrás, devido a esse fato $75 \%$ de genes compondo 
a espécie são repetidos ao longo do genoma. Isso faz com que trabalhar com os caráteres como a composição de ácidos graxos e conteúdo de óleo sejam ainda mais difíceis (SCHMUTZ et al., 2010). O melhoramento da composição do óleo de soja já acontece há mais de 50 anos e tem sido alvo devido ao fato de que a quantidade de cada ácido graxo em sua composição modifica o sabor, o tempo de prateleira ou estabilidade e o quão saudável o óleo pode ser para a dieta humana (FEHR, 2007).

O objetivo do trabalho é comparar o impacto de duas abordagens de genotipagem, SNPs gerados por GBS e SNPs gerados por microarranjo de DNA, em diferentes modelos preditivos de seleção genômica, GBLUP e BayesB, para a composição do óleo de soja. 


\section{REVISÃO BIBLIOGRÁFICA}

\subsection{A importância econômica da soja}

A última safra da soja no Brasil, de 2020/2021, tem uma área plantada de 38,2 milhões de hectares, um aumento percentual de 3,3\% desde a última safra. As previsões de produção são de 134,45 milhões de toneladas, com um aumento percentual de 7,7\% desde a última safra e colocando o país em destaque como maior produtor da oleaginosa. A média dos preços está 26,40\% mais alta que a média de novembro de 2019 e devido à alta demanda chinesa pelo grão estima-se que haverá exportação de 85 milhões de toneladas. Além disso, a demanda interna para a safra de 2020/2021 tende a manter-se aquecida devido ao aumento de produção de carnes e da mistura do biodiesel, que passará de B12 para B13. Ou seja, 13\% do diesel será proveniente do biodiesel (CONAB, 2020). Estudos de Gazzoni e Dall'agnol (2018) dizem que a demanda de soja aumentará tanto conforme o aumento da renda per capita de países de terceiro mundo e conforme a demanda da soja no mercado industrial e bioenergético nos países de primeiro mundo.

Embora a soja represente grande importância econômica ao país, a cultura também necessita de mudanças para uma produção mais sustentável. O Brasil é um dos maiores produtores de biodiesel do mundo e a soja é a cultura mais utilizada para sua produção. No entanto calcula-se que apenas $30 \%$ da energia produzida por esse biodiesel pode ser considerada renovável, já que a cadeia da soja necessita de um alto consumo de matéria e de nutrientes. As etapas de produção e processamento de soja são altamente dependentes de energia não renovável e há contaminação da fauna, solo e água por agroquímicos que são utilizados para o controle de pragas e patógenos (CAVALETT; ORTEGA, 2010). O melhoramento da soja tem como objetivo aumentar sua produtividade, tornar a cultura resistente a estresses bióticos e abióticos, melhorar sua composição química de acordo com os objetivos e o produto desejado, tornar sua cadeia de produção e produtos derivados mais sustentáveis, entre outros.

\section{2. Ácidos graxos no óleo de soja}

Os lipídeos são importantes compostos químicos para animais, plantas e microrganismos, como forma de estocagem de energia, principal constituinte da membrana plasmática, mensageiros químicos das células, entre outras importantes funções. Por definição, são compostos que solubilizam em solventes orgânicos como hexano, benzeno e clorofórmio. 
Os mais importantes lipídeos para alimentação humana são os ácidos graxos e seus derivados, os quais são ácidos carboxílicos de cadeia longa que estão ligados por uma ligação éster em um glicerol ou outros álcoois. A diferença entre óleos e gorduras é o ponto de fusão relacionado à estrutura das cadeias carbônicas dos ácidos graxos, quanto mais cadeias saturadas, mais próximas as moléculas ficam uma das outras e consequentemente maior seu ponto de fusão, assim em temperaturas ambientes as cadeias saturadas ganham uma consistência mais pastosa (CHRISTIE; HAN, 2016).

Os ácidos graxos saturados e insaturados em plantas comumente possuem 12, 14 ou 18 carbonos em uma cadeia linear com algumas ligações duplas nos insaturados. A representação de cada ácido graxo é realizada por dois números separados por dois pontos, o primeiro número representando a quantidade de carbonos na cadeia linear e o segundo número a quantidade de duplas ligações na cadeia linear. Como exemplo pode-se citar o ácido palmítico, um ácido saturado representado por 16:0, possuindo 16 carbonos na cadeia linear e nenhuma ligação dupla. Os ácidos insaturados possuem mais que duas duplas ligações e os que possuem apenas uma ligação dupla são chamados de monoinsaturados (CHRISTIE; HAN, 2016).

\subsection{Melhoramento para a composição do óleo de soja}

O melhoramento da composição do óleo de soja já acontece há mais de 50 anos e tem sido alvo devido ao fato de que a quantidade de cada ácido graxo em sua composição modifica o sabor, o tempo de prateleira ou estabilidade e o quão saudável o óleo pode ser para a dieta humana (FEHR, 2007).

Os ácidos graxos se comportam como caracteres quantitativos, os quais possuem herdabilidades de moderadas à altas (PANTHEE; PANTALONE; SAXTON, 2006). A média de ácido linolênico na soja é de 8\%, esse ácido é conhecido por produzir sabores não palatáveis depois de algum tempo na prateleira, isso acontece porque as três ligações duplas presentes nesse ácido não são estáveis e sua oxidação traz uma reversão de sabor no óleo. Por causa disso o melhoramento tem procurado diminuir a porcentagem desse ácido no óleo de cozinha (DUTTON et al., 1951).

O palmitato ou ácido palmítico (16:0) é o segundo ácido saturado mais abundante do óleo de soja, representando por volta de $11 \%$ do conteúdo total do óleo. O melhoramento do óleo direcionado ao consumo humano tem procurado diminuir o conteúdo desse ácido pois ele é indesejável à saúde humana, pois aumenta o risco de doenças cardiovasculares por possuir 
uma alta densidade e se depositar nas vias sanguíneas do sistema cardiovascular. A maioria dos programas de melhoramento são voltados para diminuir dois ácidos graxos saturados, o

palmitato e o estearato (18:0), outro ácido abundante no óleo. O primeiro grande alelo responsável pelo conteúdo de ácido palmítico, chamado de fap 1 , foi descrito por Erickson, Wilcox e Cavins (1988), após desenvolver uma linhagem mutante, a C1726 com 8,6\% de palmitato.

Mais tarde Fehr et al. (1991) conseguiram outra linhagem mutante utilizando NNitroso-N-metilureia (NMU), que é um agente cancerígeno, mutagênico e teratogênico. Essa linhagem, chamada de A22 por eles, possuía 6,8\% de ácido palmítico devido ao alelo recessivo fap3. Quando a linhagem C1726 foi cruzada com a A22, um indivíduo pertencente a progênie desse cruzamento possuía apenas 4,4\% do ácido palmítico, dando origem aos programas de melhoramento para diminuição desse ácido.

A soja convencional possui aproximadamente $25 \%$ de ácido oleico (18:1), este possui uma ligação dupla e essa característica resulta em uma maior estabilidade oxidativa e um maior tempo de prateleira. Devido a sua composição os programas de melhoramento geralmente procuram aumentar a porcentagem desse ácido no óleo total.

A soja convencional possui $52 \%$ de ácido linoleico (18:2), muitos programas têm demonstrado que a quantidade desse ácido é inversamente relacionada a quantidade do ácido oleico, ou seja, melhorar a soja para aumento de ácido oleico é o mesmo que melhorar a soja para diminuição do ácido linoleico. O ácido linoleico, por apresentar duas duplas ligações, é um ácido com facilidade para oxidar e reduzir o tempo de prateleira consequentemente. No entanto, foi documentado que o óleo com altas concentrações de ácido oleico e quantidade de ácido linolênico superior ao ácido linoleico produz odores indesejáveis (FEHR, 2007).

\subsection{Seleção genômica}

A MAS é uma técnica proposta por Lande e Thompson (1990), a qual depende da proporção da variância aditiva, da herdabilidade e o mecanismo de seleção do caráter avaliado. Essa técnica utiliza marcadores moleculares que estão associados a locos que controlam características quantitativas (QTL), indicando regiões em que há possibilidade de haver genes que possuem moderado a grande efeito. Para isso a MAS utiliza as genotipagens de famílias estruturadas e faz associações oriundas das informações fenotípicas e genotípicas. A MAS somente tem vantagem sobre a seleção fenotípica quando há uma grande população utilizada. 
Após estabelecer estatisticamente os marcadores como determinantes dos efeitos dos QTLs para cada família, então é realizada a seleção assistida por marcadores (RESENDE et al., 2008).

Alguns problemas relacionados à MAS, como a necessidade anterior à seleção de estabelecimento das associações entre marcadores e QTLs para cada família, apenas a detecção de QTLs que continham grandes efeitos na prática e necessidade de número elevado de indivíduos na família para ser superior a seleção fenotípica, levaram a proposta de um novo método de seleção, a GS (MEUWISSEN; HAYES; GODDARD, 2001). Essa seleção é denominada ampla pois utiliza as informações do genoma todo para fazer predições de genótipos que provavelmente originarão fenótipos superiores. Antes da predição genômica acontecer é necessário modelar da melhor maneira possível um evento biológico e um dos maiores entraves estatísticos da GS era que havia um número muito alto de marcadores para inferir efeito e um número muito menor de dados observados. Uma das formas encontradas para lidar com esse problema foi a utilização dos modelos mistos, um tratamento não paramétrico para capturar a complexidade de interações geradas por essas análises e o desbalanceamento de dados. Nesse tipo de análise, os parâmetros são dados como componentes de variância (GIANOLA; VAN KAAM, 2008).

A GS geralmente se baseia nos SNPs pois são marcadores que possuem alta densidade no genoma, sendo que um polimorfismo único somente pode ser considerado um marcador se explicar pelo menos $1 \%$ da variação da população. Para cada polimorfismo de nucleotídeo há possibilidade de dois alelos no caso de um organismo diploide, como há dois SNPs em um haplótipo ou intervalo, há possibilidade de quatro tipos diferentes de haplótipos. Associando as informações referentes aos marcadores e à fenotipagem é possível predizer o efeito que cada marcador possui pelo desequilíbrio de ligação entre os alelos (RESENDE, 2008).

\subsubsection{Desequilíbrio de ligação}

O desequilíbrio de ligação, ou LD (LD, do inglês Linkage Disequilibrium), é a relação não aleatória entre a frequência de dois alelos ou entre um marcador e um QTL (RESENDE et al., 2008). O equilíbrio de ligação se dá quando a frequência gamética é definida pelo produto das frequências gênicas em separado a partir das frequências alélicas da população. Em algumas condições essas frequências gaméticas observadas são diferentes das esperadas, o que indica o desequilíbrio de ligação, ou um desvio do equilíbrio. Esse desvio é nulo caso não haja alguma força de seleção na população (LEWONTIN; KOJIMA, 1960). O efeito do desequilíbrio pode 
ser observado na segregação independente dos gametas, assim a frequência de determinado gene pode estar ligada à frequência de outro, podendo ser positivamente proporcionais ou negativamente proporcionais (HARTL; CLARK, 2010). Os alelos não estão somente correlacionados devido ao grupo de ligação que eles estão nos cromossomos, alelos podem estar correlacionados mesmo em cromossomos diferentes. Forças como a seleção, co-ancestralidade e deriva genética podem fazer com que a aparição de um alelo em um gameta esteja ligada ao aparecimento de outro nesse mesmo gameta, a evolução fez com que herdar um desses alelos resultasse em uma maior probabilidade de herdar outro, e isso é vantajoso às espécies (LEWONTIN, 1988).

O desequilíbrio de ligação pode ser calculado pela variável $D$, a qual considera para o cálculo dois locos com dois alelos cada, $A, a, B$ e $b$ (HILL; ROBERTSON, 1968):

$$
\mathrm{D}=f_{A B} \cdot f_{a b}-f_{A b} \cdot f_{a B}
$$

O valor $D$ é obtido pela diferença entre as frequências dos haplótipos em associação $(A B e a b)$ e os haplótipos em repulsão (Ab e aB), a variável $D$ é o desvio do equilíbrio gerado pela recombinação dos alelos dentro dos haplótipos. Quanto mais negativo for o valor $D$, mais haplótipos em repulsão. Quanto mais positivo o valor for, maior a quantidade de haplótipos em associação.

Mesmo sendo uma medida utilizada para estudo de desequilíbrio de ligação, essa variável sofre grande influência das frequências alélicas e representa também os históricos de mudanças que ocorreram com elas. Por isso a variável muito utilizada para o cálculo de desequilíbrio de ligação é o coeficiente de determinação $\left(r^{2}\right)$, que é o coeficiente de correlação ( $r$ ) em termos quadráticos:

$$
\begin{aligned}
& \mathrm{r}=\frac{D}{\sqrt{p \cdot(1-p) \cdot r \cdot(1-r)}} \\
& r^{2}=\frac{D^{2}}{p \cdot(1-p) \cdot r \cdot(1-r)}
\end{aligned}
$$

Em termos quadráticos a direção das mudanças nas frequências não aparece, apenas a amplitude é evidenciada. Para visualização do tamanho dos blocos gênicos em cada espécie e realizar uma análise do decaimento de desequilíbrio de ligação em relação a distância dos SNPs, um gráfico do $r^{2}$ é construído partindo de uma metodologia de genotipagem, sendo que cada ponto marcado no gráfico representa o desequilíbrio de ligação entre dois SNPs diferentes ao longo do genoma todo. Quanto maior o valor de $r^{2}$, mais associados estão os dois SNPs considerados (HILL; ROBERTSON, 1968). 


\subsection{Modelos preditivos}

Algumas populações são necessárias para a GWS, a população de treinamento, a população de validação e a população de seleção. A população de treinamento é a população que contém o maior número de indivíduos para relacionar os efeitos dos QTLs com os marcadores por meio do desequilíbrio de ligação, onde cada marcador tem seu efeito estimado e um modelo preditivo é construído. Na seleção genômica não há necessidade de saber anteriormente a estrutura de parentesco das famílias presentes na população por meio de uma matriz pedigree, isso poderá ser estimado a partir dos marcadores. O Valor Genético Genômico (VGG) é obtido para cada indivíduo da população a partir da soma dos efeitos de todos os marcadores. Com o modelo construído uma nova população é utilizada no processo, a população de validação, que possui genotipagem e fenotipagem. Em muitos casos, a população de treinamento é dividida entre grupos para servir como população de treinamento e validação por meio de uma validação cruzada. E a terceira e última população é a de seleção, na qual o modelo preditivo será utilizado efetivamente (RESENDE et al., 2008; GODDARD; HAYES, 2007).

Os modelos preditivos tentam, por meio de seus parâmetros calculados, inferir a superioridade fenotípica de um indivíduo por meio das informações genômicas do mesmo. São muitos os métodos estatísticos para seleção genômica e um método pode ser considerado adequado quando comporta a arquitetura genética do caráter, levando em consideração a magnitude dos efeitos gênicos e suas distribuições, além de identificar aqueles SNPs considerados informativos. Uma das maiores dificuldades na seleção genômica é a estimação do efeito de muitos marcadores moleculares na presença de poucas informações fenotípicas. Com isso se torna necessário o uso de métodos estatísticos que fazem a regularização da estimação dos efeitos ao considerar o LD entre os alelos, ou suas colinearidades (GRATTAPAGLIA; RESENDE, 2011).

A acurácia de um método estatístico pode ser calculada pela proporção dos marcadores que explicam a variação genética e da acurácia da predição dos efeitos dos marcadores que estão em desequilíbrio de ligação com os QTLs. Quanto maior a densidade de marcadores, o desequilíbrio entre os marcadores e QTLs, a quantidade de dados para estimar os efeitos dos marcadores, além da escolha do método que melhor represente a arquitetura genética do caráter, maior a acurácia obtida (RESENDE et al., 2008).

Dois modelos que performam bem para a seleção genômica são o modelo GBLUP e o modelo BayesB (SMALLWOOD et al., 2019; DE LOS CAMPOS et al., 2013). O modelo 
GBLUP é um método de estimação penalizada de regressão explícita, o qual evita a superparametrização por meio da aplicação de um fator de penalização que consegue encurtar o efeito de um marcador de grande valor, minimizando a soma de quadrados dos resíduos, isso faz com que os efeitos de todos os marcadores tenham a mesma distribuição. O método GBLUP utiliza a matriz de parentesco estimada a partir da matriz dos marcadores. As predições representadas por este método partem do pressuposto que os locos explicam iguais variações genéticas, seguindo o modelo infinitesimal de Fisher, em que há muitos alelos de efeitos pequenos.

Já o modelo BayesB da família Bayesiana, diferentemente do modelo GBLUP, considera que pode haver diferenças nas variâncias genéticas dos locos, partindo do pressuposto que alguns locos não têm variância genética alguma e que apenas alguns estão segregando. $\mathrm{O}$ tamanho do genoma é reduzido e concentrado nas posições dos QTLs, pois muitos efeitos são assumidos como 0 a priori (RESENDE et al., 2008; GRATTAPAGLIA; RESENDE, 2011)

A expressão a seguir é utilizada para calcular o efeito dos marcadores por meio de um modelo linear misto geral:

$$
y=X b+Z h+e
$$

Na qual o $y$ representa o vetor de valores fenotípicos; $h$ representa um vetor para efeitos aleatórios gerados pelos marcadores; $Z$ é a matriz de inferência de $h$, possuindo valores de 0,1 e 2 de acordo com a quantidade de alelos para cada marcador; $b$ é o vetor de efeitos fixos; $X$ sua matriz de incidência; $e$ é referente aos resíduos. Se $h$ representa os haplótipos ao invés dos marcadores diretamente, o número de observações desse vetor é o número de marcadores vezes 4. Os valores das médias e variâncias dos componentes do modelo são representados por:

$$
\begin{aligned}
& \mathrm{h} \sim \mathrm{N}(0, \mathrm{G}) \\
& \mathrm{e} \sim \mathrm{N}\left(0, \mathrm{R}=\mathrm{I} \sigma_{e}^{2}\right) \\
& \mathrm{G}=\sum_{I}^{n} I_{h} \sigma_{i}^{2} \\
& \mathrm{E}(\mathrm{y})=\mathrm{Xb} \\
& \operatorname{Var}(\mathrm{y})=\mathrm{V}=\mathrm{ZGZ}{ }^{\prime}+\mathrm{R} \\
& \mathrm{O} \text { valor genético genômico total do indivíduo } j \text { é dado por: }
\end{aligned}
$$

$$
\mathrm{VGG}=\hat{y}_{j}=\sum_{i} Z_{i} \hat{h}_{i}
$$

Em que $i$ representa os SNPs; $Z$ possui os valores de 0,1 e 2 referentes ao genótipo do indivíduo $j$ e $\hat{h}$ o efeito predito do marcador (RESENDE, 2008). 


\subsubsection{Modelo GBLUP para estimação dos efeitos dos marcadores}

O modelo linear misto pode ser expandido para estimação de $\hat{h}$ da seguinte forma:

$$
\left[\begin{array}{cc}
X^{\prime} X & X^{\prime} Z \\
Z^{\prime} X & Z^{\prime} Z+I \frac{\sigma_{e}^{2}}{\left(\sigma_{g}^{2} / n\right)}
\end{array}\right]\left[\begin{array}{l}
\hat{b} \\
\hat{h}
\end{array}\right]=\left[\begin{array}{l}
X^{\prime} y \\
Z^{\prime} y
\end{array}\right]
$$

No qual a matriz de parentesco é representada pela matriz $Z$ 'Z; $\sigma_{g}^{2}$ é a variância genética total; $\sigma_{e}^{2}$ é a variância residual. Pode-se observar que a variância genética é dividida pelo valor total de indivíduos, característica desse modelo que considera distribuição normal para os efeitos dos marcadores, ou seja, muitos genes contribuindo para o caráter (RESENDE, 2008).

\subsubsection{Modelo BayesB para estimação dos efeitos dos marcadores}

O modelo tem um estimador que segue o teorema de Bayes:

$$
\widehat{h}=\frac{\int h * f(m \mid h) f(h) d h}{\int f(m \mid h) f(h) d h}
$$

No qual $f(m \mid h)$ representa a verossimilhança dos dados $m$ e $f(h)$ a distribuição $a$ priori dos efeitos dos QTLs. Como há probabilidade alta de que em muitas posições não haja QTL, a distribuição em $f(0)$ deve ser alta (RESENDE, 2008).

\subsection{Abordagens de genotipagem}

\subsubsection{Chip de DNA}

Com o Sequenciamento de Nova Geração (SNG) foi possível criar a plataforma de genotipagem por chip de DNA e evidenciar a variabilidade entre indivíduos, mostrando diferenças em translocações, inversões e polimorfismos em apenas um nucleotídeo. Para formação de um chip uma máquina deposita, em inúmeros pontos conhecidos de uma lâmina de vidro, pequenas partes de DNA que servirão para ancorar sondas chamadas de arranjos. Essas pequenas sequências podem representar o genoma todo ou apenas pontos de polimorfismo em uma dada espécie. Esses chips de DNA, ou microarranjos de DNA, são utilizados para inúmeras funções, como a análise de expressão gênica de um organismo em determinado estado fisiológico e metabólico e para genotipagem de uma população que será submetida a seleção ou análise de diversidade (GRIFFITHS et al., 2013). 
Para utilização de um chip em estudo de expressão gênica diferencial, células são submetidas a extração de RNA total que terá marcações fluorescentes para serem utilizados como sondas, cada organismo terá uma cor de marcação e essa amostra será depositada no chip. As sondas se ligarão às sequências homólogas de DNA dispostas no chip e um scanner com laser será utilizado para emitir as fluorescências, dessa forma pode-se observar o padrão de cores nos pontos conhecidos e inferir qual alelo está presente em cada amostra (GRIFFITHS et al., 2013).

\subsubsection{Genotyping-By-Sequencing}

A genotipagem por sequenciamento (GBS) é uma técnica que realiza a descoberta de marcadores na mesma etapa em que faz a genotipagem (CROSSA et al., 2013). A técnica é simples, tem uma relação boa entre custo e benefício relacionado aos outros métodos de genotipagem e produz altas acurácias quando utilizada na seleção genômica (JARQUíN et al., 2014). A técnica é capaz de identificar SNPs e InDels que podem não ser reconhecidos em um chip de DNA, pois a descoberta dos marcadores é realizada para a população em estudo, não de forma geral como é construído nos chips comerciais de DNA. Também pode ser aplicada tanto em organismos que já possuem um genoma de referência assim como os que não possuem, importante destacar que a quantidade de SNPs descobertos caso seja utilizado um genoma de referência é maior que a quantidade de SNPs se não utilizado (ELSHIRE et al., 2011).

Depois de realizar a extração de DNA, enzimas são utilizadas para realizar cortes em toda sua extensão, pode-se utilizar enzimas de cortes raros ou frequentes dependendo do objetivo da genotipagem e do quanto se quer cobrir do genoma. Para próxima etapa são utilizados barcodes, que são sequências de DNA específicas que servirão como adaptadores nos sítios de corte das enzimas utilizadas anteriormente. São utilizados inúmeros barcodes e adaptadores comuns para ligar aos inúmeros fragmentos de DNA, já que é um experimento multiplex, que mistura as amostras. Posteriormente segue-se para amplificação dos fragmentos em PCR (Polymerase Chain Reaction), os primers utilizados são compatíveis aos adaptadores. O sequenciamento somente será realizado nos fragmentos que tiverem um barcode ligado em uma extremidade e um adaptador comum na outra extremidade. Fragmentos muito grandes apresentam problemas para a formação da ponte na técnica de PCR e não serão sequenciados devido a isso. Depois de realizar o sequenciamento, os barcodes serão alinhados em um genoma 
de referência utilizando técnicas de bioinformática. Alguns filtros são aplicados aos SNPs descobertos nessa etapa, como a frequência alélica mínima (ELSHIRE et al., 2011). 


\section{MATERIAL E MÉTODOS}

\subsection{Material vegetal e dados fenotípicos}

Para representar a diversidade da composição do óleo de soja foram utilizados 96 acessos originários dos germoplasmas da Embrapa-Soja e do Departamento de Genética, ESALQ/USP. Desses 96 acessos, 62 eram de Introdução de Plantas (IP) e 34 eram cultivares não aparentadas. As sementes foram dispostas em um delineamento de blocos aumentados entre novembro e março em dois anos consecutivos, nos anos de 2009-2010 e 2010-2011, com cada ano contendo 6 blocos e cada bloco contendo 20 tratamentos. Dentre esses 20 tratamentos, 4 eram comuns em todos os blocos e 16 eram regulares. Cada tratamento era representado por 20 plantas dispostas com espaçamento de 0,8 metros uma da outra e em uma linha de 1,5 metros de comprimento. De cada parcela foram retiradas 100 gramas de sementes para amostragem.

A extração do óleo total foi realizada utilizando o solvente hexano pelo método de Butt, no Instituto Agronômico de Campinas (IAC), em São Paulo, Brasil. Os perfis de ácidos graxos foram construídos a partir de uma cromatografia gasosa (PRIOLLI et al., 2019).

\subsection{Modelo e análise fenotípica}

O seguinte modelo estatístico para análise fenotípica foi utilizado em duas etapas:

$$
y_{i j k}=u+b_{i}+g_{j}+a_{k}+e_{i j k}
$$

Na primeira etapa, $y$ representa o fenótipo médio em nível de parcela do campo e varia de acordo com o efeito do bloco $(i)$, o efeito do genótipo $(j)$, o efeito do ano $(k)$ e o erro ou resíduo. Na primeira etapa o efeito do bloco é tratado como aleatório e o efeito do genótipo e ano são tratados como fixos. O fenótipo é representado pela soma de:

$u=$ Uma média geral;

$b_{i}=\mathrm{O}$ efeito do bloco $i$, com $i$ variando de 1 a 6 blocos;

$g_{j}=\mathrm{O}$ efeito do genótipo $j$, com $j$ variando de 1 a 96 genótipos;

$a_{k}=\mathrm{O}$ efeito do ano $k$, com $k$ variando de 1 a 2 anos;

$e_{i j k}=\mathrm{O}$ resíduo ou erro, variando de acordo com o bloco, genótipo e ano avaliado;

Para estimar as variâncias genéticas e herdabilidades usou-se o mesmo modelo, mas com o efeito do genótipo e bloco considerados aleatórios, essa metodologia foi seguida a partir dos estudos de Dias et al. (2020), que apresentaram os melhores resultados para a seleção genômica. A interação do genótipo com o ano $(j \times k)$ não foi considerada pois o delineamento 
de blocos aumentados fez com que nem todos os genótipos aparecessem nos dois anos considerados, então essa interação foi deixada como resíduo por não ser significativa no modelo.

Uma distribuição normal foi assumida e uma matriz VCOV foi indexada para o fator ano. Duas estruturas de VCOV foram testadas, ID (ID, do inglês Identical Variation) e DIAG (DIAG, do inglês Heterogeneous variation), que são estruturas considerando homogeneidade e heterogeneidade de variâncias residuais, respectivamente. Estas foram avaliadas via critérios AIC (AKAIKE, 1974) e BIC (SCHWARZ, 1978).

Depois de avaliar a melhor estrutura de variância, 92 médias ajustadas (BLUEs, do inglês Best Linear Unbiased Estimation) (HENDERSON, 1975) e os parâmetros genéticos foram estimados, como a variância genética, variância residual, coeficiente de variação e herdabilidade de Cullis (CULLIS; SMITH; COOMBES, 2006). Esse processo foi realizado para cada um dos caracteres.

Nos modelos mistos com dados desbalanceados, o teste F não se aplica para testar os componentes de variância genéticos, já que estes são calculados como efeitos aleatórios. Nesse caso, o teste mais recomendado é o teste LRT (LRT, do inglês Likelihood Ratio Test) ou Teste de Razão de Verossimilhança.

\subsection{Análise genotípica}

Dados de duas abordagens de genotipagem foram utilizadas nos modelos, a genotipagem por um chip de DNA, o BarcSoySNP6k (Illumina Infinum BeadChips) (SONG et al., 2020) e os SNPs gerados por GBS (Genotyping-By-Sequencing). Para ambos os métodos, os acessos foram plantados em bandejas de germinação e o DNA foi extraído de um bulk de folhas de cinco plantas de cada acesso utilizando o DNeasy Plant Kit (Qiagen). As bandejas foram colocadas em casa de vegetação, com temperatura de 24-25 graus Celsius e 33\% de umidade. A genotipagem do chip foi realizada no Centro de Genômica Funcional ESALQ/USP em Piracicaba, São Paulo, Brasil (PRIOLLI et al, 2019).

O método de genotipagem por GBS foi realizado utilizando dois tipos de enzimas de restrição, uma de corte raro, a enzima NsiI (New England BioLabs Inc. ®), e outra de corte frequente, a enzima MseI (New England BioLabs Inc. ()). Somente foram utilizados os fragmentos que possuíam um corte realizado pela enzima de corte raro em uma extremidade e na outra extremidade um corte realizado pela enzima de corte frequente. O barcode estava 
localizado no adaptador gerado pela enzima NsiI, adaptador que também foi utilizado como sítio pelo primer na etapa de amplificação por PCR. O sequenciamento foi do tipo single-end, realizado no Hemocentro de Ribeirão Preto, São Paulo, Brasil, pela plataforma Illumina NextSeq 500 (Illumina, San Diego, CA, EUA) para a produção de fragmentos de 150 pb de comprimento.

$\mathrm{O}$ resultado do sequenciamento estava em formato FastQ, formato que permite visualizar a sequência do read, a localização de sua lane e flowcell e a qualidade de cada base pelo seu $Q$ score gerado, valor que denota a probabilidade daquela base ter sido lida corretamente. A qualidade do sequenciamento das duas abordagens foi verificada utilizando uma ferramenta de diagnóstico dos dados gerados, o software FastQC v. 0.11.5 (Brabahan Bioinformatics). Na chamada dos SNPs (SNP calling) foi utilizado o pipeline TASSEL-GBS (GLAUBITZ et al., 2014) e o alinhamento com o genoma de referência da soja, Williams v.4, foi realizado utilizando o software Bowtie2 (LANGMEAD; SALZBERG, 2013). Novamente no TASSEL foram aplicados filtros como MAF (MAF, do inglês Minor Allele Frequency) maior que 0,05, CR (CR, do inglês Call. Rate) máximo de 0,75 e Het (Het, do inglês Heterozygotes) maior que 0,10. Como uma das características da GBS é a quantidade de dados perdidos, uma imputação de SNPs foi realizada a fim de recuperar alguns dados, para essa tarefa foi utilizado o software Beagle v. 5.1 (BROWNING; BROWNING, 2007). O formato final de saída das genotipagens foi o VCF, por fim o pacote VCFTools (DANECEK et al., 2011) foi utilizado para aplicar o filtro MAF nos dados recuperados.

\subsection{Comparação dos métodos de genotipagem}

\subsubsection{Coeficientes de Correlação de Pearson}

O coeficiente de correlação de Pearson (r) é um coeficiente que demonstra o quão relacionadas estão duas variáveis quantitativas (PUTH; NEUHÄUSER; RUXTON, 2014). Para evidenciar o impacto das genotipagens na seleção genômica, uma matriz com coeficientes de correlação de Pearson a partir da matriz de parentesco (VANRADEN, 2008) foi construída para motivos de comparação entre as duas metodologias de genotipagem utilizadas no trabalho. $\mathrm{Na}$ matriz foram avaliadas as seguintes quatro combinações:

(I) Genotipagem por GBS com dados filtrados (GBS_F)

(II) Genotipagem por GBS com dados não filtrados (GBS_NF)

(III) Genotipagem por 6K com dados filtrados (6K_F) 
(IV) Genotipagem por 6K com dados não filtrados (6K_NF)

\subsubsection{Análise de componentes principais}

Uma Análise de Componentes Principais (PCA, do inglês Principal Component Analysis) foi realizada a partir da matriz de parentesco para cada uma das genotipagens, esse tipo de análise é uma técnica estatística de análise multivariada que diminui a quantidade de dados e por transformar linearmente os dados, retira a correlação entre as variáveis sem perder informações sobre esse conjunto. É uma técnica designada ao propósito de explicar a variância e covariância das variáveis. Ela age de forma a juntar indivíduos que explicam uma variância similar para a característica (HONGYU; SANDANIELO; OLIVEIRA-JR, 2015). Adicionalmente a PCA, foram construídos Heatmaps para cada abordagem de genotipagem a partir da matriz de parentesco.

\subsection{Comparação entre os modelos preditivos}

Dois modelos possuem uma boa performance para a seleção genômica, GBLUP e o modelo BayesB (SMALLWOOD et al., 2019). O modelo BayesB foi utilizados por meio do pacote "BGLR" (DE LOS CAMPOS et al., 2013), enquanto que o modelo GBLUP foi utilizado por meio do pacote ASReml-R, v. 3.0 (BUTLER et al., 2019), ambos no ambiente R (R CORE TEAM, 2015).

Para comparar os modelos, uma validação cruzada (10 k-fold) foi realizada 20 vezes. Em cada uma dessas 20 repetições, todos os indivíduos foram separados em 10 grupos aleatoriamente e cada grupo foi utilizado como população de validação, enquanto os outros 9 compunham a população de treinamento do modelo. Com esses 9 grupos para treinamento do modelo e o grupo de validação, duas formas de avaliar a capacidade preditiva das metodologias foram utilizadas, o Erro Médio Quadrático de Predição (EMQP) e a acurácia preditiva. Em cada grupo buscou-se a representação dos dois grupos presentes na população utilizada, a mesma proporção de plantas que foram introduzidas e cultivares. A avaliação foi com base nas quatro combinações formadas pelos métodos e pelas genotipagens:

(I) Genotipagem por chip e modelo GBLUP (6K_GBLUP)

(II) Genotipagem por chip e modelo BayesB (6K_BayesB)

(III) Genotipagem por GBS e modelo GBLUP (GBS_GBLUP) 
(IV) Genotipagem por GBS e modelo BayesB (GBS_BayesB)

Cada uma dessas combinações foi analisada para os seis caracteres seguintes:

(I) Ácido linoleico

(II) Ácido linolênico

(III) Ácido oleico

(IV) Ácido palmítico

(V) Ácido esteárico

(VI) Óleo total

Seguindo o que foi realizado no trabalho de (DIAS et al., 2020), para a avaliação da performance e capacidade preditiva dos modelos foram calculadas a acurácia preditiva e o Erro Médio Quadrático de Predição (EMQP). A acurácia preditiva foi calculada como a correlação entre os valores genômicos preditos e as médias ajustadas pelos diferentes modelos. Já o EMQP foi calculado por meio da fórmula:

$$
\mathrm{EMQP}=\sum_{i=1}^{n} \frac{\left(\hat{y}_{i}-y_{i}\right)^{2}}{n}
$$

Como o EMQP representa a diferença do valor fenotípico predito pelo valor real, quanto menor o valor da EMQP, maior a capacidade preditiva. 


\section{RESULTADOS}

\subsection{Análise fenotípica}

A Figura 1 ilustra a correlação entre os caracteres avaliados no trabalho para a composição do óleo e suas distribuições. O ácido palmítico não possui uma correlação estatística significativa apenas com um dos caracteres, o óleo total. Enquanto o ácido esteárico possui correlação significativa com apenas um ácido, o ácido palmítico. A correlação mais alta foi entre o ácido oleico e o linoleico, com uma correlação negativa de -0,95.

Figura 1. Correlação entre os caracteres avaliados.

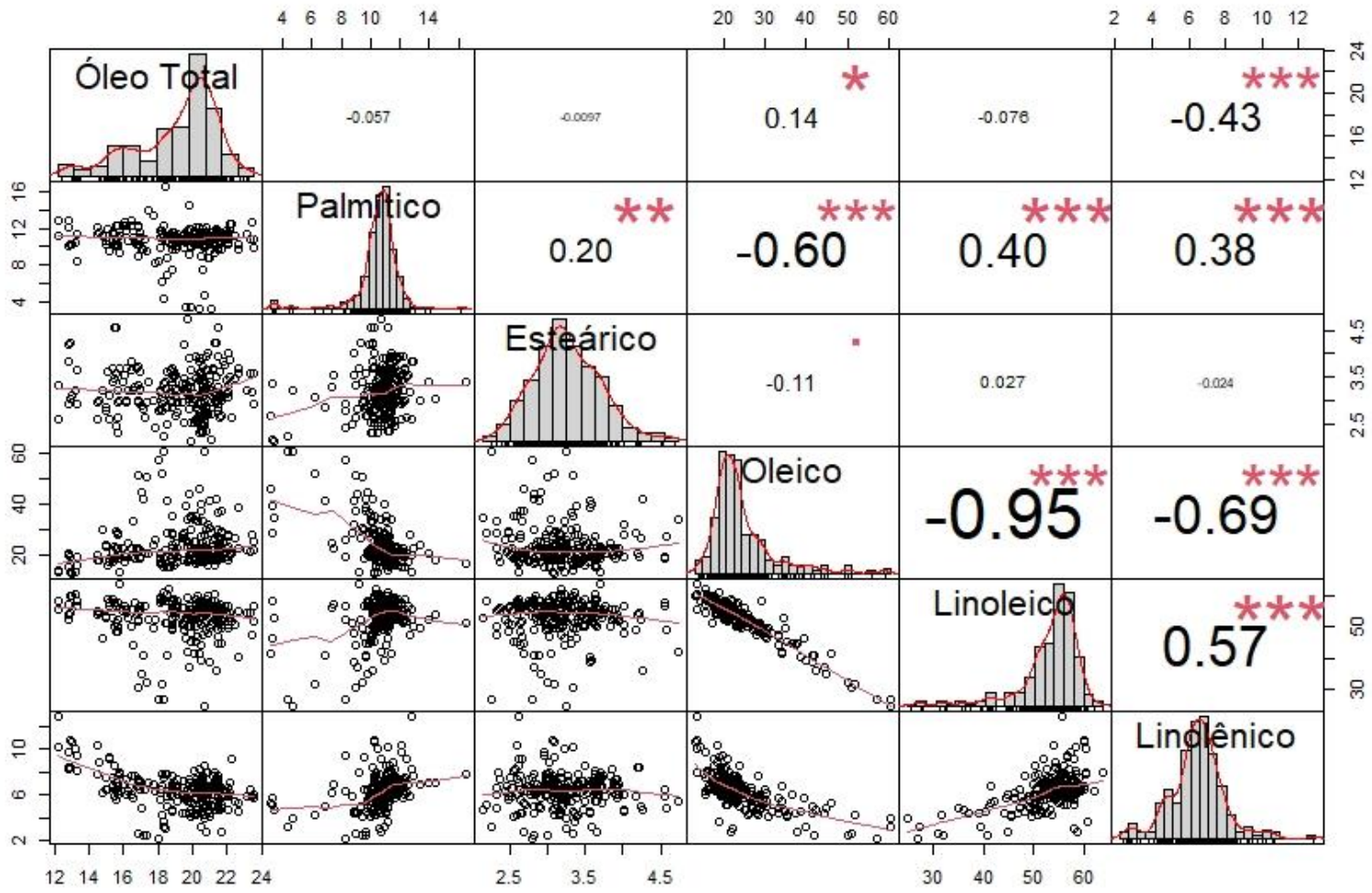

Fonte: Própria, 2021.

Notas:

* Resultados estatisticamente significantes

Os critérios AIC e BIC, que testavam homogeneidade e heterogeneidade de variâncias, foram realizados para escolha de estrutura da variância residual. O óleo total, o ácido palmítico, o ácido esteárico e o ácido linolênico obtiveram um melhor ajuste assumindo uma variância residual homogênea. Já os ácidos linoleico e oleico tiveram um melhor ajuste utilizando a variância residual heterogênea (Tabela 1). 
Tabela 1. Análise de variâncias residuais.

\begin{tabular}{ccccccc}
\hline Caráter & \multicolumn{2}{c}{ LogLik } & \multicolumn{2}{c}{ AIC } & \multicolumn{2}{c}{ BIC } \\
& Homo & Het & Homo & Het & Homo & Het \\
\hline Óleo & $-104,09$ & $-103,38$ & $212,18^{*}$ & 212,77 & $217,99^{*}$ & 221,49 \\
Palmítico & $-18,97$ & $-18,81$ & $41,94^{*}$ & 43,63 & $47,75^{*}$ & 52,35 \\
Esteárico & 52,53 & 53,72 & $-101,07^{*}$ & $-101,45$ & $-95,26^{*}$ & $-92,73$ \\
Oleico & $-291,37$ & $-286,75$ & 584,74 & $577,50^{*}$ & 587,64 & $583,31^{*}$ \\
Linoleico & $-254,63$ & $-248,31$ & 511,26 & $502,63^{*}$ & 514,17 & $511,35^{*}$ \\
Linolênico & $-82,88$ & $-82,41$ & $167,76^{*}$ & 168,82 & $170,66^{*}$ & 174,63 \\
\hline
\end{tabular}

Fonte: Própria, 2021.

Notas:

* Melhores resultados entre variâncias residuais heterogêneas e homogêneas

Homo - Variância homogênea

Het - Variância heterogênea

A Tabela 2 mostra as médias ajustadas e desvios padrão dos acessos regulares e dos utilizados como testemunhas. As maiores variâncias genéticas e residuais e os maiores coeficientes de variação foram do ácido oleico e linoleico. A análise revelou que todos os componentes genômicos calculados são estatisticamente significantes pelo teste de Razão de Verossimilhança. A maior herdabilidade foi do ácido palmítico, com um valor de 0,95 e a pior herdabilidade foi a partir do ácido esteárico, com um valor de 0,74.

Tabela 2. Análise fenotípica dos resultados.

\begin{tabular}{cccccccc}
\hline Caráter & $\begin{array}{c}\text { Média } \\
\text { Testemunhas }\end{array}$ & $\begin{array}{c}\text { Média } \\
\text { Regulares }\end{array}$ & VG & VE & CV & Hc & LRT \\
\hline Óleo & 21 & 18,8 & 5,24 & 0,93 & 5,13 & 0,91 & $133^{*}$ \\
& $(20,5-21)$ & $(12,9-23,3)$ & & & & & \\
Palmítico & 11 & 10,6 & 2,67 & 0,26 & 4,89 & 0,95 & $218^{*}$ \\
& $(10,5-11,5)$ & $(3,51-15,51$ & & & & & \\
Esteárico & 3 & 3,22 & 0,13 & 0,09 & 2,88 & 0,74 & $44,6^{*}$ \\
& $(2,48-3,41)$ & $(2,16-4,55)$ & & & & & \\
Oleico & 23,8 & 24,6 & 57,50 & 15,5 & 37,2 & 0,88 & $117^{*}$ \\
& $(19,9-30,1)$ & $(13,3-56,2)$ & & & & & \\
Linoleico & 53,1 & 52,8 & 35,00 & 9,02 & 28,4 & 0,89 & $121^{*}$ \\
& $(49,3-55,7)$ & $(28,2-61,1)$ & & & & & \\
Linolênico & 6,38 & 6,36 & 1,77 & 0,70 & 7,95 & 0,83 & $76^{*}$ \\
& $(5,19-7,54)$ & $(2,41-11,59)$ & & & & & \\
\hline
\end{tabular}

Fonte: Própria, 2021.

Notas:

* Significante a $\mathrm{p}<0.01$.

Parênteses denotam desvio-padrão

VG - Variância Genética

VE - Variância do Erro ou Residual

CV - Coeficiente de Variação

Hc - Herdabilidade de Cullis

LRT - Teste de razão de verossimilhança 


\subsection{Análise genotípica}

\subsubsection{Coeficientes de Correlação de Pearson}

A quantidade de SNPs pelo método 6K antes da filtragem era de 5835 SNPs, após a filtragem e imputação a quantidade de SNPs pelo mesmo método era de 5425 SNPs. Enquanto a quantidade de SNPs pelo método GBS antes da filtragem e imputação era de 21014 SNPs, e depois ficaram apenas 7133 SNPs.

Os coeficientes de correlação de Pearson calculados a partir da matriz de parentesco estão representados na Tabela 3.

Tabela 3. Coeficientes de Correlação de Pearson para os métodos de genotipagem com e sem filtragem.

\begin{tabular}{ccccc}
\hline & GBS_F & GBS_NF & 6K_NF & 6K_F \\
\hline GBS_F & 1 & - & - & - \\
GBS_NF & 0,610 & 1 & - & - \\
6K_NF & 0,724 & 0,257 & 1 & 1 \\
6K_F & 0,771 & 0,300 & 0,973 & \\
\hline
\end{tabular}

Fonte: Própria, 2021.

Notas:

F - SNPs Filtrados

NF- SNPs Não Filtrados

A genotipagem realizada pelo $6 \mathrm{~K}$ possui um coeficiente de 0,973 entre os dados filtrados e não filtrados. Já a genotipagem realizada por GBS possui um coeficiente de 0,610 entre os dados filtrados e não filtrados. Os SNPs não filtrados gerados por GBS possuem um coeficiente de 0,300 em relação aos SNPs filtrados gerados por 6K, a partir do momento em que se filtram os dados de GBS sua correlação com os dados filtrados do chip passa a ser 0,771. Os dados filtrados de GBS possuem um coeficiente de 0,724 com os dados não filtrados do $6 \mathrm{~K}$. Assim que se realiza a filtragem dos dados do $6 \mathrm{~K}$, o coeficiente de correlação passa a ser 0,771. O coeficiente mais baixo representado na tabela é o coeficiente de correlação entre os SNPs não filtrados gerados por GBS com os SNPs não filtrados gerados pelo $6 \mathrm{~K}$, com um valor de 0,257 de correlação.

\subsubsection{Análise de componentes principais}

A Figura 2 mostra o resultado da Análise dos Componentes Principais do método de genotipagem por 6K. Nela o Componente Principal 1 (CP1) é responsável por 31,69\% da 
variação e o Componente Principal 2 (CP2) é responsável por 14,47\% da variância. É possível visualizar com essa figura que há uma maior variação no grupo de Introdução de Plantas (IP) do que no grupo das cultivares (C) e uma leve distinção entre os dois grupos considerados.

Figura 2. Análise de Componentes Principais da genotipagem por chip de DNA.

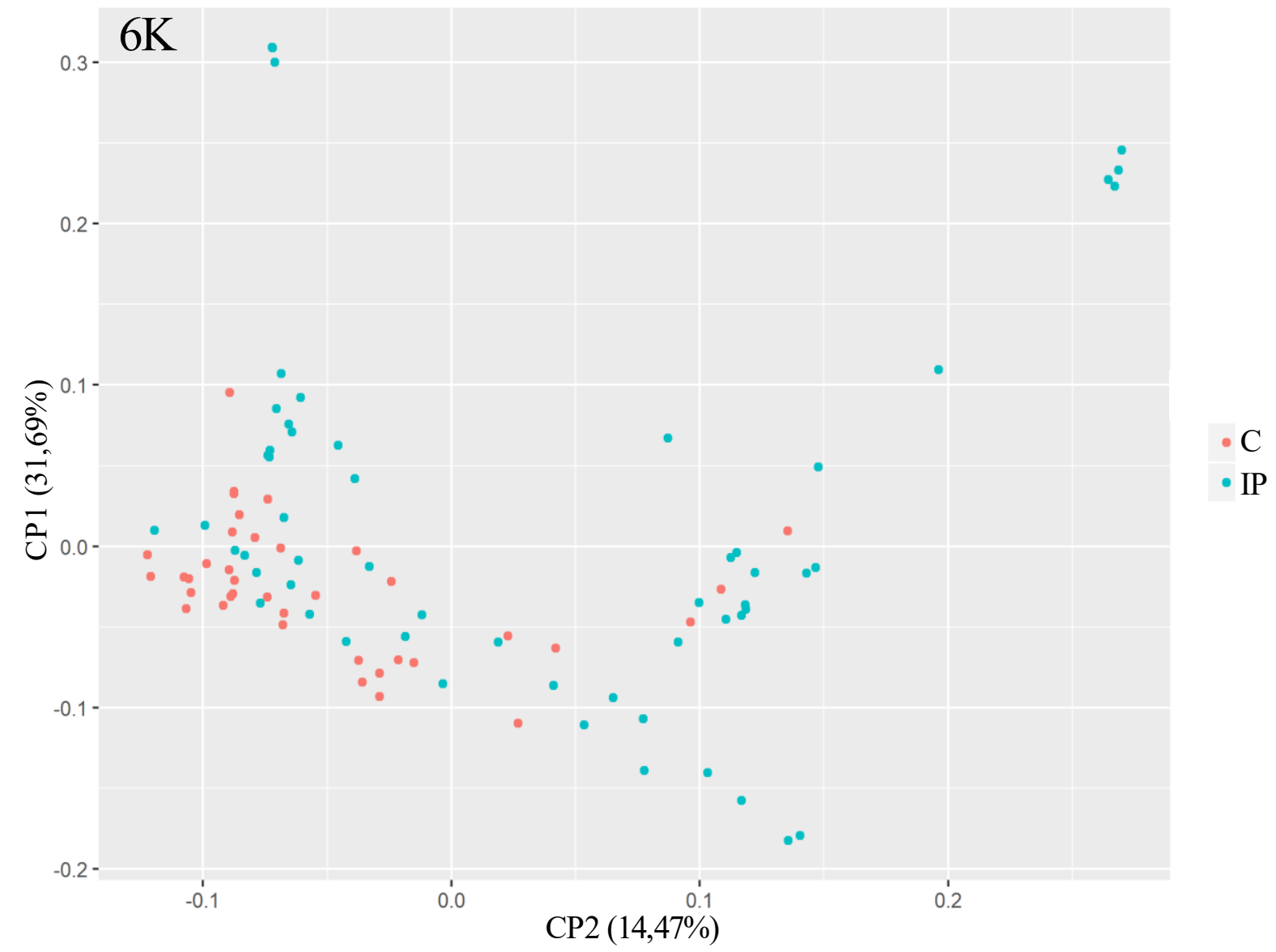

Fonte: Própria, 2021.

A Figura 3 mostra o resultado da Análise dos Componentes Principais do método de genotipagem por GBS. Nela o Componente Principal 1 (CP1) é responsável por $24,5 \%$ da variação e o Componente Principal 2 (CP2) é responsável por 16,28\% da variância. Não é possível visualizar separação entre os grupos de Introdução de Plantas (IP) e grupo das cultivares $(\mathrm{C})$, nem mesmo uma maior variação entre as PIs. 
Figura 3. Análise de Componentes Principais da genotipagem por GBS com dados filtrados.

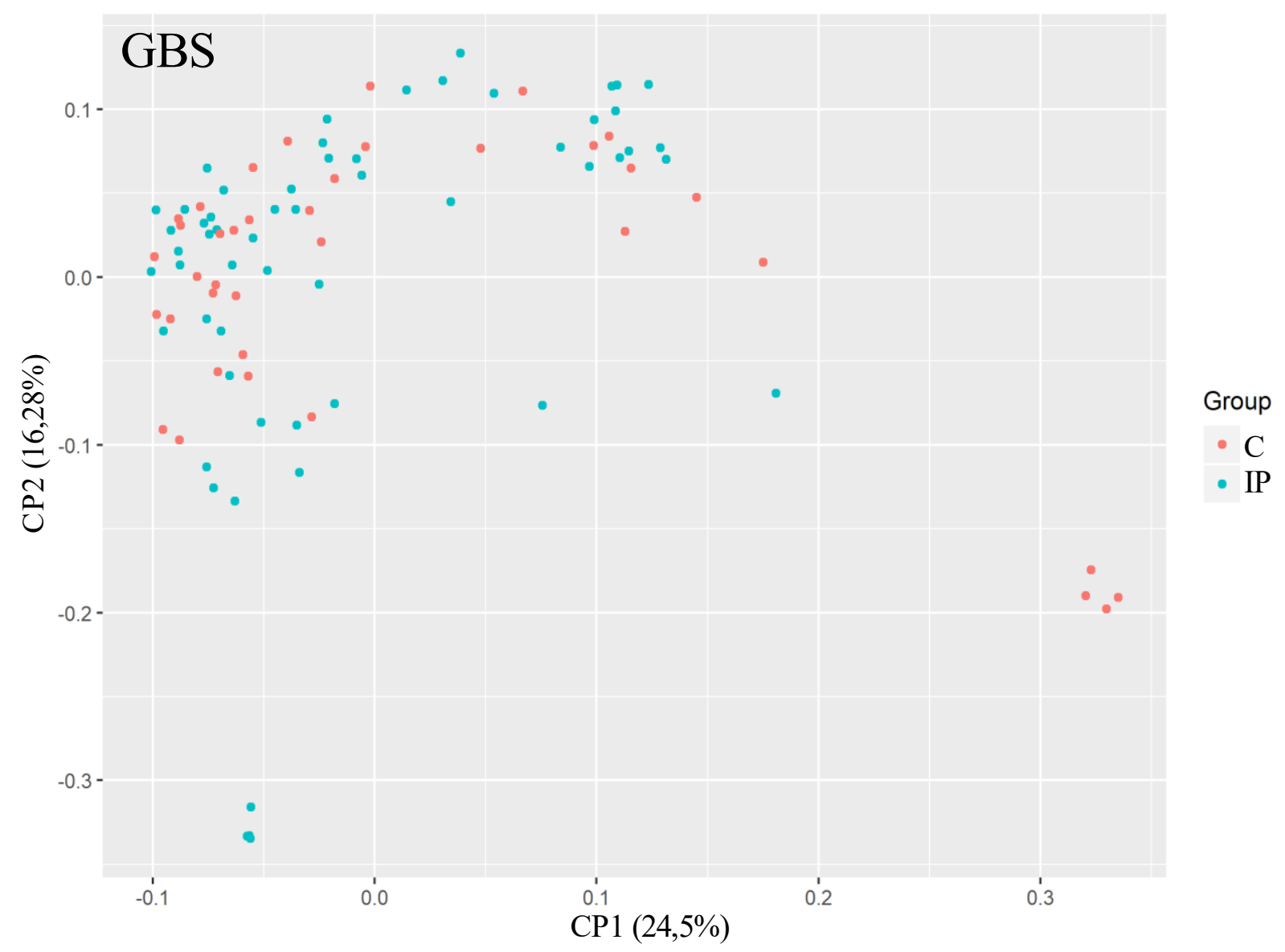

Fonte: Própria, 2021.

A Figura 4 mostra os Heatmaps a partir das matrizes de parentesco para cada genotipagem. O método 6K delimita de forma mais clara os grupos de Introdução de Plantas e Cultivares. O método GBS não delimita os grupos de forma tão clara, embora seja possível visualizar a distinção entre esses grupos.

Figura 4. Heatmaps das matrizes de parentesco de cada um dos métodos de genotipagem.

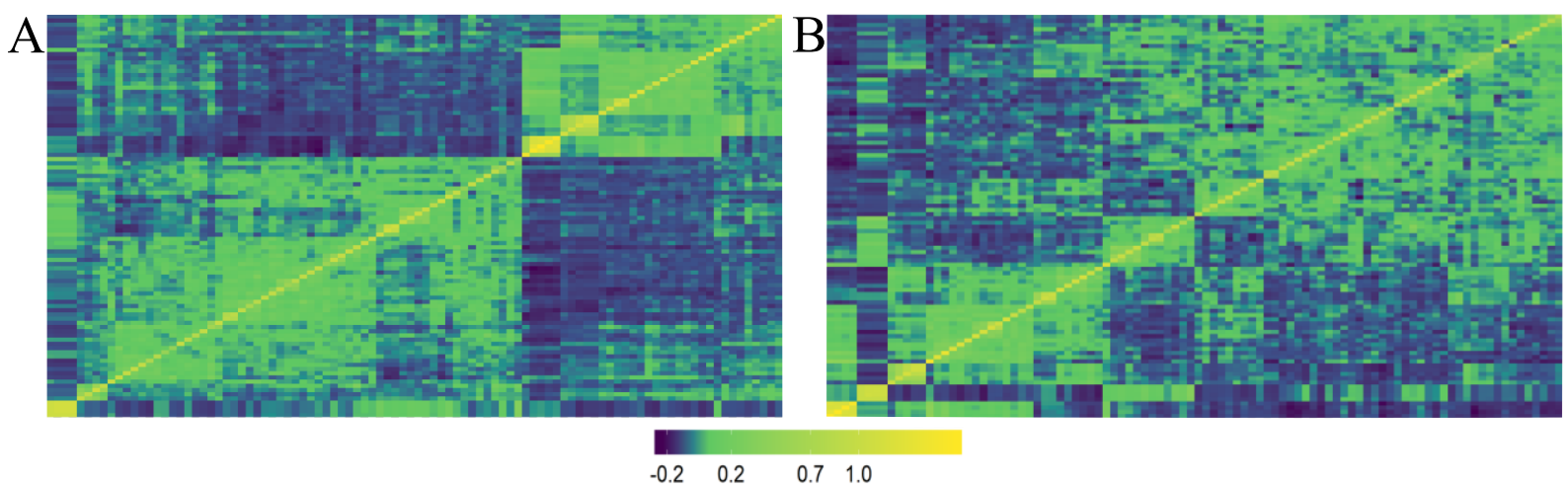

Fonte: Própria, 2021.

Notas:

A - Heatmap da matriz de parentesco de método $6 \mathrm{~K}$

B - Heatmap da matriz de parentesco do método GBS. 


\subsection{Análise da capacidade preditiva dos modelos estatísticos}

\subsubsection{Erro Médio Quadrático de Predição}

O Erro Médio Quadrático de Predição foi calculado para todas as combinações entre os modelos preditivos e abordagens de genotipagem. A Figura 5 evidencia o boxplot dos resultados obtidos e na Tabela $\mathbf{4}$ as médias e desvios padrão são apresentados como dados suplementares para a discussão dos resultados obtidos.

Para o ácido linoleico a maior capacidade preditiva foi obtida pelo método de genotipagem por 6K com o modelo GBLUP, resultando em um EMQP médio de 25,6, o menor valor obtido por meio do menor erro médio quadrático de predição. A combinação GBS_ GBLUP obteve um valor de EMPQ de 31,32, a combinação 6K_BayesB resultou em um valor de 26,29 e a combinação GBS_BayesB resultou em um valor de 32,04, esse último resultando na maior média entre todas as combinações para esse caráter. Juntamente com o ácido oleico, esses dois ácidos obtiveram as piores capacidades preditivas calculadas a partir do EMQP.

Para o ácido linolênico as capacidades preditivas foram muito próximas entre os modelos e métodos de genotipagem. O menor valor para predizer esse caráter foi obtido por meio da combinação 6K_GBLUP, com um valor de EMQP médio de 1,27.

Figura 5. Erro Médio Quadrático de Predição (EMQP) dos métodos e genotipagens utilizados.

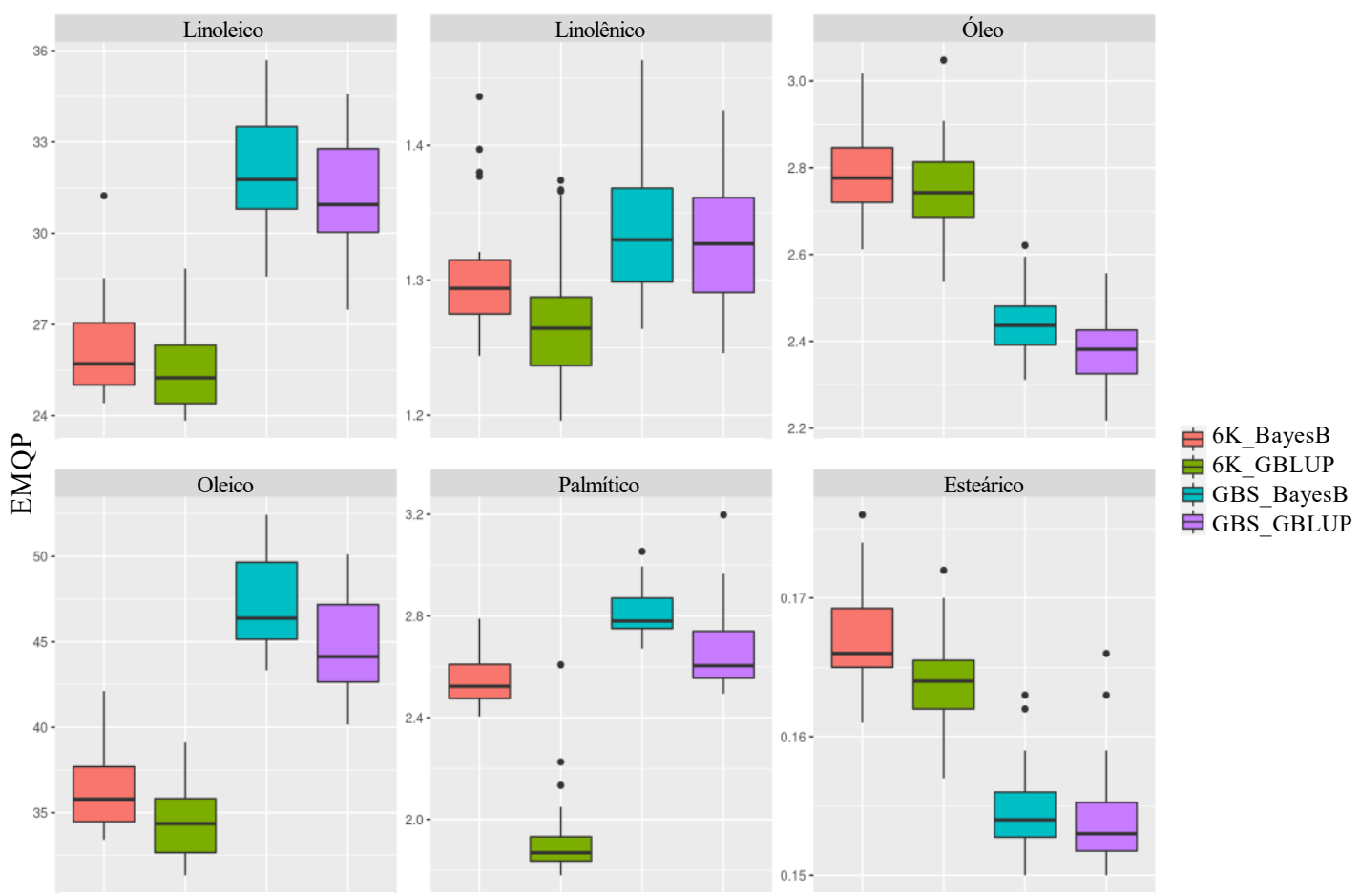

Fonte: Própria, 2021. 
As combinações a partir do óleo total não apresentaram grandes diferenças, porém uma maior capacidade preditiva foi apresentada pela abordagem de genotipagem por GBS e pelo modelo GBLUP, com um valor médio de EMPQ de 2,38.

O ácido oleico foi o ácido que apresentou os maiores desvios padrão das combinações e os piores valores de EMQP entre todos os caracteres avaliados. A genotipagem por $6 \mathrm{~K}$ no modelo BayesB obteve um EMQP médio de 36,4, enquanto a mesma genotipagem no modelo GBLUP obteve um valor médio de 34,56. O método GBS no modelo BayesB apresentou um EMQP médio de 47,17 e o modelo GBLUP apresentou um EMQP médio de 44,89.

O ácido palmítico apresentou um EMPQ de 2,55 para a combinação 6K_BayesB, um valor de 2,82 para o GBS_BayesB e um valor de 2,68 para GBS_GBLUP. A melhor combinação foi 6K_GBLUP, com um EMPQ médio de 1,94.

O ácido esteárico produziu as melhores capacidades preditivas a partir dos EMQP, visto que são os menores números apresentados entre todos os caracteres, com os menores desvios padrão entre todos os caracteres.

\subsubsection{Análise da acurácia preditiva dos modelos}

As acurácias dos modelos, conforme os caracteres avaliados e as genotipagens, são representadas na Figura 6. A Tabela 5 apresenta as médias e desvios padrão, apresentados como dados suplementares para a discussão dos resultados obtidos. 
Figura 6. Acurácia preditiva dos modelos preditivos conforme os métodos de genotipagem

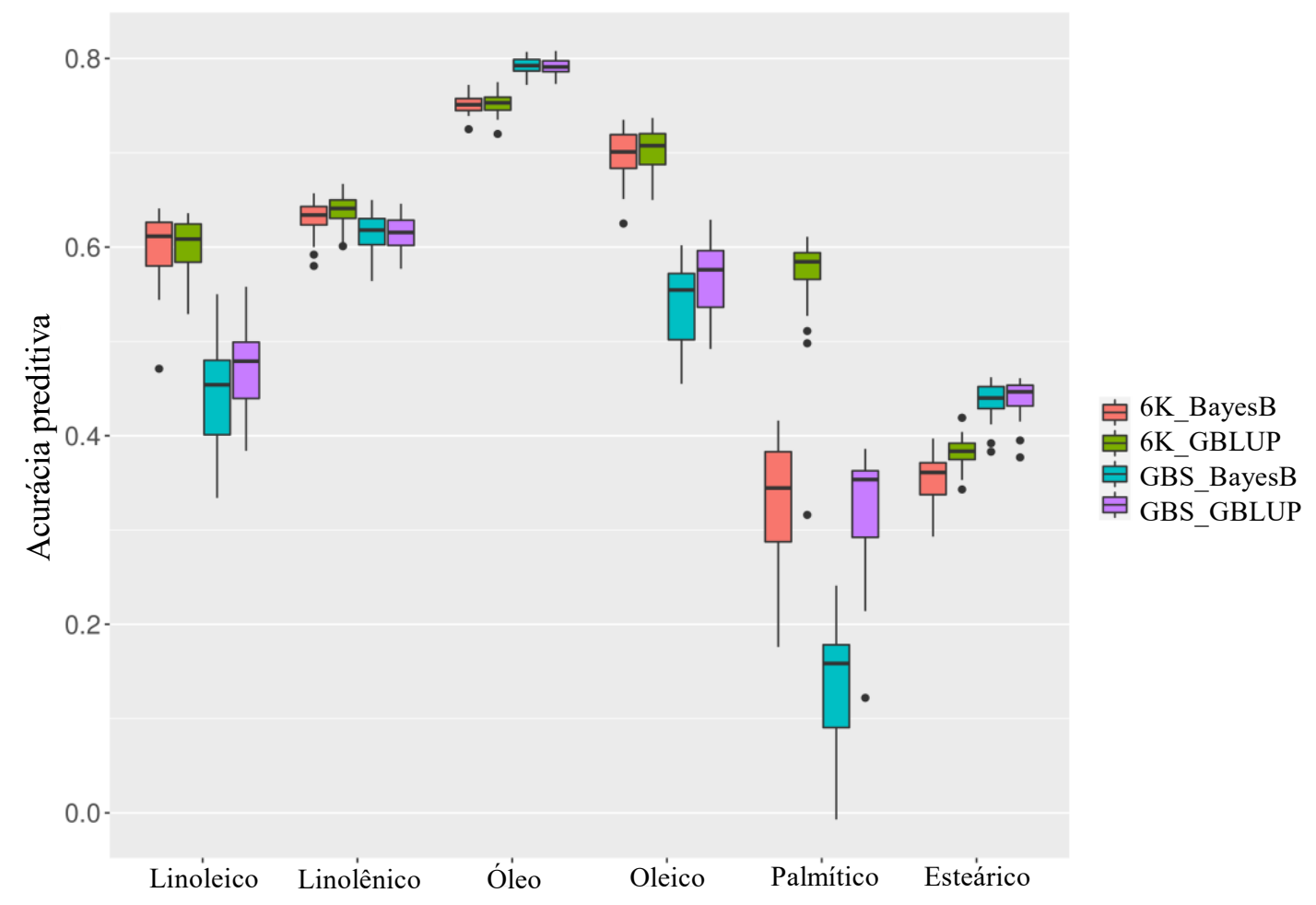

Fonte: Própria, 2021.

A maior acurácia obtida foi para o óleo total, com o modelo chegando a aproximadamente $80 \%$ de acurácia para o método GBS e $76 \%$ para o método $6 \mathrm{~K}$.

O caráter que obteve maior diferença entre os modelos e genotipagens foi o ácido palmítico. Com a combinação 6K_GBLUP com uma acurácia de 56\% e a combinação GBS_BayesB com uma acurácia média de 14\%. Já as combinações 6K_BayesB e GBS_GBLUP resultaram em uma acurácia preditiva média de 32\%. Esse caráter obteve os maiores desvios padrão entre os caracteres avaliados.

As predições realizadas para o ácido linoleico apresentaram uma acurácia média de $60 \%$ para o método 6K, uma acurácia média de 44\% para a combinação GBS_BayesB e uma acurácia média de 47\% para a combinação GBS_GBLUP.

O ácido linolênico apresentou acurácia de 63\% com a combinação 6K_BayesB, 64\% com a combinação 6K_GBLUP, 62\% com a combinação GBS_BayesB e $61 \%$ com a combinação GBS_GBLUP.

O ácido oleico foi predito nos modelos com uma acurácia de $70 \%$ para o método $6 \mathrm{~K}$ em ambos os modelos estatísticos. E para o método GBS, o modelo BayesB resultou em uma acurácia de 54\% e o modelo GBLUP em uma acurácia de 57\%. 
Os melhores resultados para o ácido esteárico foram obtidos utilizando o método GBS, com $44 \%$ de acurácia para os dois modelos estatísticos. A genotipagem $6 \mathrm{~K}$ resultou em uma acurácia média de 35\% para o modelo BayesB e 38\% para o modelo GBLUP. 


\section{DISCUSSÃO}

O objetivo do trabalho era comparar o impacto das abordagens de genotipagem nos modelos preditivos de seleção genômica, GBLUP e BayesB, para a composição do óleo de soja. A composição do óleo de soja foi avaliada por meio da análise dos principais ácidos graxos presentes no óleo, são eles o ácido linoleico, o ácido linolênico, o ácido oleico, o ácido palmítico e o ácido esteárico, além de considerar o óleo total. Para isso, plataformas de genotipagem foram exploradas a partir da matriz de parentesco conforme os índices de correlação de Pearson, análise dos componentes principais e pelos resultados obtidos nos modelos preditivos. Já a capacidade preditiva dos modelos foi analisada a partir da acurácia preditiva e do erro médio quadrático de predição.

A genotipagem por sequenciamento e a genotipagem por chip de DNA são abordagens complementares para a detecção de locos quantitativos em estudos de associação genômica (NEGRO et al., 2019). Porém, a utilização das duas metodologias concomitantemente não é a abordagem mais vantajosa para um programa de melhoramento, pois o custo final ainda é alto, o tempo de análises computacionais também deve ser levado em consideração e utilizar apenas uma abordagem pode levar a resultados satisfatórios, com cada metodologia podendo ser superior de acordo com o caráter avaliado e com a espécie estudada (DE MORAES et al., 2018). Nesse aspecto reside a importância do trabalho, já que não há muitos trabalhos na literatura que avaliam modelos preditivos e abordagens de genotipagem para a composição do óleo de soja.

Em seu trabalho, De Moraes et al. (2018) avaliam o impacto de duas formas de genotipagem em população de eucalipto, população derivada de duas espécies do gênero Eucalyptus. Nesse trabalho, embora os dois métodos de genotipagem tenham tido resultados satisfatórios, o chip de DNA se mostrou superior ao método GBS na maioria dos caracteres avaliados no que diz respeito a cobertura e densidade de SNPs no genoma do eucalipto. Isso aconteceu devido ao fato de que estudos extensivos para a formação de chips de DNA foram realizados para essa espécie. Porém, os coeficientes de herdabilidade e acurácia dos modelos preditivos foram muito similares entre as duas metodologias. Ou seja, a falta de cobertura dos SNPs no genoma não impactou na predição dos modelos estatísticos e embora uma abordagem tenha se saído superior a outra, a utilização de qualquer uma delas para a seleção desses caracteres, na população e espécie consideradas, seria satisfatória.

A abordagem de obtenção de SNPs por meio de plataformas de sequenciamento e enzimas de restrição tem se tornado uma opção cada vez mais atrativa. Jarquín et al. (2014) demonstram que a utilização dessa plataforma tem grande potencial para o uso na seleção 
genômica para produtividade da soja. Além disso, demonstram que uma população de treinamento de pequeno a moderado tamanho, filtro de apenas 5\% de MAF e um modelo GBLUP robusto que considera apenas o efeito aditivo, já apresentam resultados satisfatórios utilizando essa abordagem de genotipagem.

A genotipagem por GBS resulta em alta porcentagem de dados perdidos e necessita de uma imputação de SNPs, ou recuperação de dados, após a filtragem. A recuperação desses dados perdidos depende do LD, já que grandes blocos de LD fazem com que a precisão na imputação seja maior. Isso quer dizer que nessa espécie as taxas de recombinações são menores e há mais associações alélicas, esses haplótipos servem como base para recuperação dos dados na imputação (WANG et al., 2016). O estudo de associação genômica ampla para a composição do óleo de Priolli et al (2019), utilizando essa população e genotipagem, mostra que os blocos de LD na soja são longos e o decaimento é devagar, sugerindo uma boa recuperação dos dados perdidos.

Como evidenciado na Tabela 3, a partir do momento em que se realiza a filtragem e imputação dos SNPs do GBS, sua correlação com SNPs filtrados do 6K passa para 0,771, evidenciando a recuperação de grande parte dos dados perdidos. No entanto para o método 6K, o coeficiente entre os dados filtrados e não filtrados é de 0,973 . Ou seja, não houve muita diferença após utilizar os mesmo filtros e imputação de SNPs nessa plataforma. Esses dados mostram as características de cada método, onde em um houve extensivos estudos de polimorfismos na espécie e assim foi formada uma plataforma comercial para o uso no melhoramento, e no outro um resultado específico gerado para os caracteres avaliados e para a população e enzimas utilizadas. Isso também é observável nas Figura 2, 3 e 4, onde mostram que o método 6K delimita de forma mais clara os grupos de Introdução de Plantas e Cultivares, enquanto o método GBS não delimita os grupos de forma tão clara, embora seja possível visualizar a distinção entre esses grupos.

Para espécies com uma base genética mais estreita como a do gado bovino, que possuem origem em pequeno número de animais, a genotipagem por chip pode ser largamente utilizada em programas de melhoramento do mundo todo (GIBBS; TAYLOR; TASSELL, 2009). Já as plantas alógamas, que possuem uma base genética ampla, não podem utilizar uma mesma plataforma para todos os programas de melhoramento. Como o método GBS depende de sítios de restrição de enzimas para realizar os cortes, com enzimas podendo ser de corte raro e/ou frequente, essa plataforma pode detectar muitos alelos raros e específicos para uma população de interesse e embora o chip seja uma plataforma bem consolidada, acaba excluindo esses alelos raros que poderiam ser úteis para seleção (DE MORAES et al., 2018). 
A soja é uma espécie paleoalotetraploide que resultou de duas duplicações genômicas que aconteceram a 13 e 59 milhões de anos atrás, devido a esse fato $75 \%$ de genes compondo a espécie são repetidos ao longo do genoma. Isso faz com que trabalhar com os caracteres como a composição de ácidos graxos e conteúdo de óleo sejam ainda mais difíceis, pois há muitas informações redundantes (SCHMUTZ et al., 2010). Liu et al. (2020) e Leamy et al. (2017) demonstram que todos os ácidos estão correlacionados uns aos outros, alguns em maior proporção que outros, para melhorar a soja em relação a composição do óleo é necessário se ater as estruturas genéticas de cada um desses caracteres e como eles estão correlacionados.

A análise fenotípica resultou em valores de herdabilidade que variaram de 0,74 a 0,95 (Tabela 2). Herdabilidades altas são favoráveis para seleção, já que quanto maior for o valor do coeficiente de herdabilidade, maior a acurácia preditiva e maiores são os efeitos estimados para os marcadores com proximidade aos QTLs (PÉRTILE et al., 2016). No entanto o ácido palmítico resultou em um padrão inesperado, obteve acurácias abaixo da média entre os outros caracteres avaliados (Tabela 5), mas obteve a maior herdabilidade (Tabela 2). Todas as combinações mostraram resultados diferentes entre si, não havendo uma semelhança entre as combinações que levavam o mesmo método de genotipagem, nem uma semelhança entre as combinações que resultaram do mesmo modelo preditivo (Figura 5 e 6). Além disso, esse ácido resultou nos maiores desvios padrão de acurácia (Tabela 5) e no maior intervalo interquartílico (Figura 6). Na validação cruzada, os grupos utilizados como população de validação continham a mesma porcentagem de cultivares e introdução de plantas que a população de treinamento, então essa diferença do ácido palmítico não resultou de um problema de amostragem, já que havia boa representatividade.

A busca por genótipos de soja contendo baixos conteúdos de ácido palmítico se dá devido ao risco de doenças cardiovasculares. Goettel et al. (2016) verificou que quando um genótipo era homozigoto em relação ao gene FATB1a, este possuía um conteúdo de ácido palmítico de 9,8\%, que é relativo ao conteúdo de cultivares comerciais. Quando o genótipo era heterozigoto, o conteúdo de ácido palmítico era 5,4\% e quando uma deleção era realizada em ambos os alelos do gene, o conteúdo de ácido palmítico chegava em 4,2\%.

Reações enzimáticas na cadeia do metabolismo dos ácidos graxos são geralmente determinados por mais de dois genes equivalentes, criando redundância de efeitos (PHAM et al., 2010). Na soja há três genes mutantes em uma família denominada FAD2 (FAD2, do inglês Fatty Acid Desaturase 2). Dois deles geralmente são expressos nas sementes, sendo comprovado que quando os dois aparecem de uma vez, o conteúdo de ácido oleico é significativamente maior, pois não há a conversão em ácido linoleico, resultando em um 
acúmulo de ácido oleico (PHAM et al., 2011). A rota metabólica dos ácidos graxos pode ser visualizada na Figura 7.

Figura 7. Rota metabólica dos ácidos graxos.

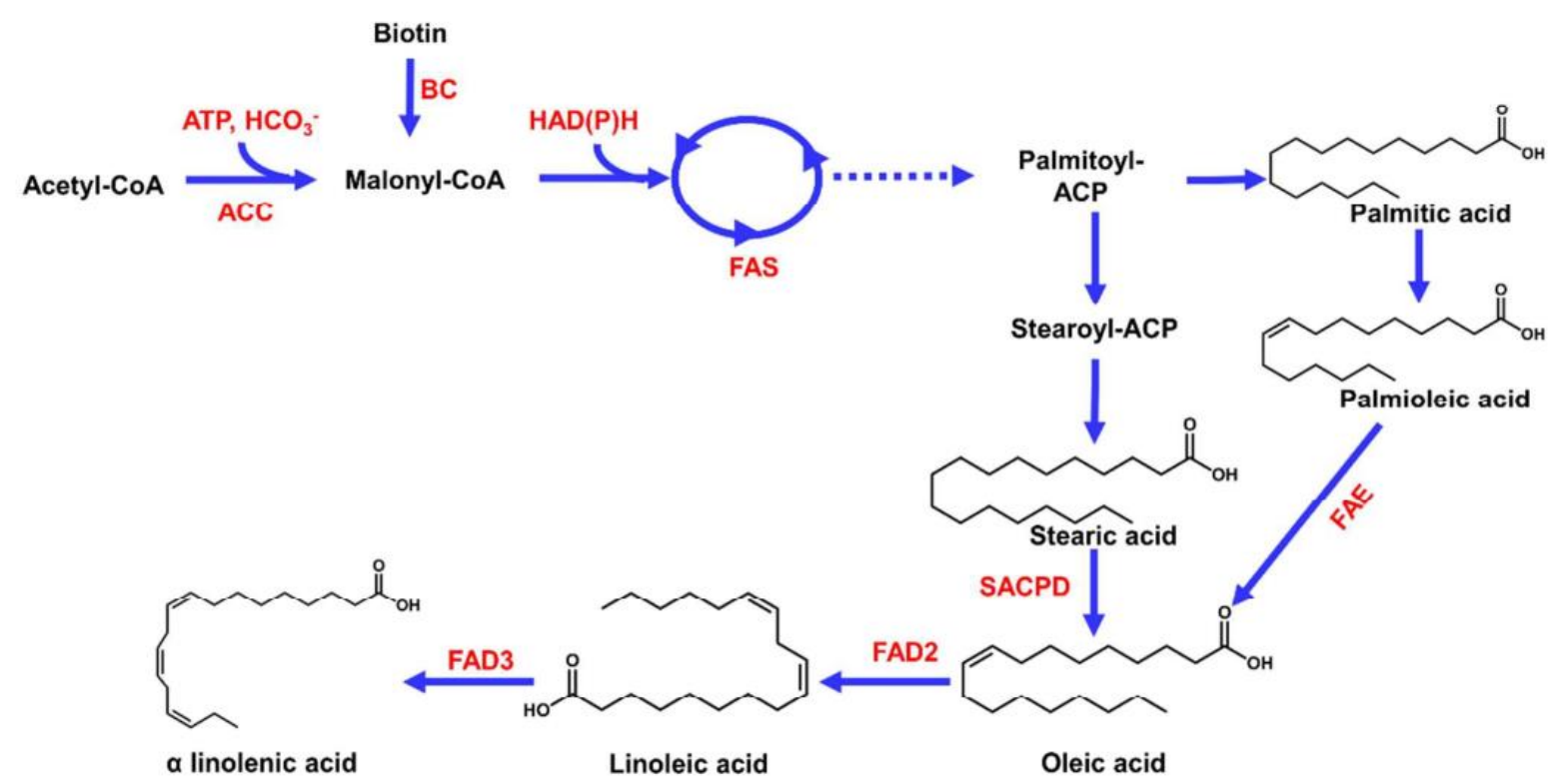

Fonte: YANG et al., 2017.

A segunda herdabilidade mais alta foi a do conteúdo de óleo total, com um valor de 0,91 (Tabela 2). Condizente com esse resultado, sua acurácia preditiva também obteve os maiores valores. Os dois modelos preditivos utilizados resultaram em valores semelhantes de acurácia e a diferença obtida foi devido aos métodos de genotipagem. O método por GBS conseguiu uma acurácia de $80 \%$ e o método 6K uma acurácia de $75 \%$ (Tabela 5), ambas as combinações com um EMQP muito próximo a zero (Figura 6, Tabela 4), demonstrando uma capacidade preditiva alta em relação às acurácias preditivas encontradas para esse caráter na literatura e aos outros caracteres do trabalho (SMALLWOOD et al., 2019). Como o Erro Médio Quadrático de Predição é uma forma de dizer o quão longe os resultados preditos ficavam dos resultados observados, quanto menor seu valor, melhor a capacidade preditiva.

O ácido oleico e o linoleico resultaram em padrões semelhantes entre eles, ambos tiveram uma herdabilidade muito próxima, 0,88 e 0,89, respectivamente. Ambos os caracteres também resultaram nas maiores variâncias genéticas e residuais e os maiores coeficientes de variação consequentemente. O EMQP de ambos os ácidos foram os maiores entre todos os caracteres avaliados, chegando a uma média de 32,04 para o ácido linoleico pelo método GBS_BayesB e uma média de 47,17 para o ácido oleico na mesma combinação de genotipagem e modelo. A menor média para ambos os ácidos foi conseguida pela combinação 6K_GBLUP 
e a acurácia preditiva para ambos os ácidos se saiu melhor utilizando a genotipagem $6 \mathrm{~K}$ de modo geral.

Essas similaridades encontradas nas análises podem indicar uma estrutura genética semelhante controlando o caráter. Leamy et al., (2017) mostram em seus estudos que a maior correlação entre os caracteres considerados no trabalho é entre esses dois ácidos, com uma correlação negativa de $-0,78$, significativa estatisticamente. Da mesma forma, a correlação desses dois ácidos no presente trabalho foi alta e significante, com uma correlação significativa de -0,95. Ou seja, assim como exposto na Figura 7, o ácido oleico é um precursor do ácido linoleico, sem o qual não há sua produção e eles são inversamente proporcionais. Se não há a conversão para ácido linoleico, há um acúmulo de ácido oleico. O ácido linoleico, por apresentar duas duplas ligações, é um ácido com facilidade para oxidar e reduzir o tempo de prateleira, então o objetivo dos programas de melhoramento para o óleo de cozinha tem procurado diminuí-lo (FEHR, 2007). Já um óleo de soja com grande quantidade de ácido oleico significa um óleo com maior quantidade de ácidos graxos monoinsaturados e isso ajuda a minimizar vários problemas cardiovasculares. Além do fato de que um aumento no nível de ácidos monoinsaturados pode melhorar a estabilidade oxidativa, não havendo a necessidade de hidrogenação (MERCER; WYNNE; YOUNG, 1990; SHI et al., 2015)

A herdabilidade mais baixa entre todos os ácidos foi gerada a partir dos dados de ácido esteárico, com um valor de 0,74 . Sua acurácia preditiva juntamente com o ácido palmítico foram as piores entre todos os caracteres analisados, com um valor de $40 \%$ de acurácia geral média. No entanto, o modelo obteve o EMQP geral mais próximo a zero. 


\section{CONCLUSÃO}

Como a composição do óleo, ou o conteúdo de cada ácido graxo, faz parte de uma mesma rota metabólica, é necessário um grande estudo para que os níveis de todos os ácidos graxos sejam adequados para cada objetivo e utilização final desse óleo. O óleo de soja é utilizado para diversas funções, então os perfis de ácidos graxos no óleo são diferentes para cada objetivo, fazendo do trabalho um importante estudo e direcionamento para o melhoramento da composição do óleo de soja.

O caráter com maior acurácia entre todas as combinações utilizadas no trabalho foi o óleo, com quase $77 \%$ de acurácia geral e a pior acurácia entre todos os caracteres foi a do ácido palmítico com $33 \%$ de acurácia geral. A combinação que gerou a maior acurácia preditiva e menor erro médio quadrático de predição para o ácido palmítico foi 6K_GBLUP. Para o ácido esteárico foram as combinações GBS_BayesB e GBS_GBLUP com os mesmos valores para as duas combinações, tanto pelo EMQP e acurácia preditiva. Para o ácido oleico foi a combinação 6K_GBLUP. Para o ácido linoleico foi a combinação 6K_GBLUP. Para o ácido linolênico foi a combinação 6K_GBLUP. E para o óleo total a combinação GBS_GBLUP.

De forma geral a plataforma de genotipagem que resultou nos melhores resultados foi a de microarranjo de DNA, mais especificamente o BarcSoySNP6k (Illumina Infinum BeadChips) (SONG et al., 2020) e o modelo preditivo que resultou nos melhores valores foi o GBLUP. 


\section{REFERÊNCIAS}

AKAIKE, H. A New Look at the Statistical Model Identification. IEEE Transactions on Automatic Control, v. 19, n. 6, p. 716-723, 1974. DOI: 10.1109/TAC.1974.1100705.

BROWNING, S. R.; BROWNING, B. L. Rapid and accurate haplotype phasing and missingdata inference for whole-genome association studies by use of localized haplotype clustering. American Journal of Human Genetics, v. 81, n. 5, p. 1084-1097, 2007. DOI: $10.1086 / 521987$.

BUTLER, D. G.; CULLIS B. R.; GILMOUR A. R., GOGEL B. J., 2009. Manual de referência do pacote ASReml-R.

DE LOS CAMPOS, G.; PÉREZ, P.; VAZQUEZ, A. I.; CROSSA, J. Genome-Enabled Prediction Using the BLR (Bayesian Linear Regression) R-Package Gustavo. Methods in Molecular Biology, v. 1019, p. 437-447, 2013. DOI: 10.1007/978-1-62703-447-0.

CAVALETT, O.; ORTEGA, E. Integrated environmental assessment of biodiesel production from soybean in Brazil. Journal of Cleaner Production, v. 18, n. 1, p. 55-70, 2010. DOI: 10.1016/j.jclepro.2009.09.008.

CHRISTIE, W. W.; HAN, X. Lipid analysis: Isolation, Separation, Identification and Lipidomic Analysis. 4. ed. Oily Press, 2010.

CONAB. Acomp. safra brasileira de grãos, v.8 - Safra 2020, n. 3- Terceiro levantamento, Brasília, p. 1-86, 2020.

COSTA, J. A. Cultura da soja. Porto Alegre: Manica, 1996. 233 p.

CROSSA, J.; BEYENE, Y.; SEMAGN, K.; PÉREZ, P.; HICKEY, J. M.; CHEN, C.; DE LOS CAMPOS, G.; BURGUEÑO, J.; WINDHAUSEN, V. S.; BUCKLER, E.; JANNINK, J. L.; CRUZ, M. A. L.; BABU, R. Genomic prediction in maize breeding populations with genotyping-by-sequencing. G3: Genes, Genomes, Genetics, v. 3, n. 11, p. 1903-1926, 2013. DOI: $10.1534 / \mathrm{g} 3.113 .008227$. 
CULliS, B. R.; SMITH, A. B.; COOMBES, N. E. On the design of early generation variety trials with correlated data. Journal of Agricultural, Biological, and Environmental Statistics, v. 11, n. 4, p. 381-393, 2006. DOI: 10.1198/108571106X154443.

DANECEK, D. P.; AUTON, A.; ABECASIS, G.; ALBERS, C. A.; BANKS, E.; DEPRISTO, M. A.; HANDSAKER, R. E.; LUNTER, G.; MARTH, G. T.; SHERRY, S. T.; MCVEAN, G.; DURBIN, R. The variant call format and VCFtools. Bioinformatics, v. 27, n. 15, p. 2156-2158, 2011. DOI: 10.1093/bioinformatics/btr330.

DE LOS CAMPOS, G.; HICKEY, J. M.; PONG-WONG, R.; DAETWYLER, H. D.; CALUS, M. P. L. Whole-genome regression and prediction methods applied to plant and animal breeding. Genetics, v. 193, n. 2, p. 327-345, 2013. DOI: 10.1534/genetics.112.143313.

DE MORAES, B. F. X.; SANTOS, R. F.; LIMA, B. M.; AGUIAR, A. M.; MiSSIAGGIA, A. A.; DIAS, D. C.; REZENDE, G. D. P. S.; GONÇALVES, F. M. A.; ACOSTA, J.J.; KIRST, M.; RESENDE, M. F.R.; MUÑOZ, P. R. Genomic selection prediction models comparing sequence capture and SNP array genotyping methods. Molecular Breeding, v. 38, n. 115, p. 1-14, 2018. DOI: 10.1007/s11032-018-0865-3.

DIAS, K. O.G.; PIEPHO, H. P.; GUIMARÃES, L. J.M.; GUIMARÃES, P. E.O.; PARENTONI, S. N.; PINTO, M. O.; NODA, R. W.; MAGALHÃES, J. V.; GUIMARÃES, C. T.; GARCIA, A. A.F.; PASTINA, M. M.. O. G. et al. Novel strategies for genomic prediction of untested single-cross maize hybrids using unbalanced historical data. Theoretical and Applied Genetics, v. 133, p. 443-455, 2020. DOI: 10.1007/s00122-01903475-1.

DUTTON, H. J.; LANCASTER, C. R.; EVANS, C. D.; COWAN, J. C. The Flavor Problem of Soybean Oil. The Journal of the American Oil Chemists' Society, v. 28, p. 115-118, 1951.

ELSHIRE, R. J.; GLAUBITZ, J. C.; SUN, Q.; POLAND, J. A.; KAWAMOTO, K.; BUCKLER, E. S.; MITCHELL, S. E. A robust, simple genotyping-by-sequencing (GBS) approach for high diversity species. PLoS ONE, v. 6, n. 5, p. 1-10, 2011. DOI: 10.1371/journal.pone.0019379. 
ERICKSON, E. A.; WILCOX, J. R.; CAVINS, J. F. Inheritance of Altered Palmitic Acid Percentage in Two Soybean Mutants. Journal of Heredity, v. 79, p. 465-468, 1988.

FEHR, W. R.; WELKE, G. A.; HAMMOND, E. G.; DUVICK, D. N.; CIANZIO, S. R.; MERR, L. Inheritance of Reduced Palmitic Acid Content in Seed Oil of Soybean. Crop Science, v. 31, p. 88-89, 1991.

FEHR, W. R. Breeding for modified fatty acid composition in soybean. Crop Science, v. 47, n. S3, p. 72-87, 2007. DOI: 10.2135/cropsci2007.04.0004IPBS.

GAZZONI, D. L.; DALL'AGNOL, A. A saga da soja: de 1050 a.C. a 2050 d.C. Brasília, DF: Embrapa, 2018. 199 p.

GIBBS, R. A.; TAYLOR, J. F.; TASSELL, C. P. V. Variation Uncovers the Genetic. Science, v. 324, p. 528-532, 2009.

GLAUBITZ, J. C.; CASSTEVENS, T. M.; LU, F.; HARRIMAN, J.; ELSHIRE, R. J.; SUN, Q.; BUCKLER, E. S. TASSEL-GBS: A high capacity genotyping by sequencing analysis pipeline. PLoS ONE, v. 9, n. 2, 2014. DOI: 10.1371/journal.pone.0090346.

GODDARD, M. E.; HAYES, B. J. Genomic selection. J. Anim. Breed. Genet., v. 124, p. $323-$ 330, 2007. DOI: 10.1007/978-81-322-2316-0_10.

GOETTEL, W.; RAMIREZ, M.; UPCHURCH, R. G.; AN, C. Identification and characterization of large DNA deletions affecting oil quality traits in soybean seeds through transcriptome sequencing analysis. Theoretical and Applied Genetics, v. 129, p. 1577-1593, 2016. DOI: $10.1007 / \mathrm{s} 00122-016-2725-\mathrm{z}$.

GRATTAPAGLIA, D.; RESENDE, M. D. V. Genomic selection in forest tree breeding. Tree Genetics and Genomes, v. 7, p. 241-255, 2011. DOI: 10.1007/s11295-010-0328-4.

GRIFFITHS, A. J. F; WESSLER, S. R.; CARROLL, S. B.; DOEBLEY, J. Introdução à Genética. 10. Ed. Rio de Janeiro: Guanabara Koogan, 2013. 736 p. 
HENDERSON, C. R. Best linear unbiased estimation and prediction under a selection model. Biometrics. v. 2, p. 423-447, 1975.

HILL, W. G.; ROBERTSON, A. Linkage Disequilibrium in Finite Populations. Theoretical and Applied Genetics, v. 38, p. 226-231, 1968. DOI: 10.1080/03071848408522227.

HONGYU, K.; SANDANIELO, V. L. M.; OLIVEIRA, G. J. Análise de Componentes Principais: resumo teórico, aplicação e interpretação. E\&S - Engineering and Science, v. 5, n. 1, p. 83-90, 2015. DOI: 10.18607/ES20165053.

JARQUÍN, D.; KOCAK, K.; POSADAS, L.; HYMA, K.; JEDLICKA, J.; GRAEF, G.; LORENZ, A. Genotyping by sequencing for genomic prediction in a soybean breeding population. BMC Genomics, v. 15, n. 1, p. 1-10, 2014. DOI: 10.1186/1471-2164-15-740.

LANDE, R.; THOMPSON, R. Efficiency of marker-assisted selection in the improvement of quantitative traits. Genetics, v. 124, n. 3, p. 743-756, 1990.

LANGMEAD, B.; SALZBERG, S. L. Fast gapped-read alignment with Bowtie 2. Nature Methods, v. 9, n. 4, p. 357-359, 2013. DOI: 10.1038/nmeth.1923.

LEAMY, L. J.; ZHANG, H.; LI, C.; CHEN, C. Y.; SONG, B. A genome-wide association study of seed composition traits in wild soybean (Glycine soja). BMC Genomics, v. 18, n. 18, p. 1-15, 2017. a. DOI: 10.1186/s12864-016-3397-4.

LEWONTIN, R. C. On measures of gametic disequilibrium. Genetics, v. 120, n. 3, p. 849-852, 1988.

LEWONTIN, R. C.; KOJIMA, K. The Evolutionary Dynamics of Complex Polymorphisms. Evolution, v. 14, n. 4, p. 458-472, 1960. DOI: 10.2307/2405995.

LIU, X.; QIN, D.; PIERSANTI, A.; ZHANG, Q.; MICELI, C.; WANG, P. Genome-wide association study identifies candidate genes related to oleic acid content in soybean seeds. BMC Plant Biology, v. 20, n. 399, p. 1-14, 2020. 
MERCER, L. C.; WYNNE, J. C.; YOUNG, C. T. Inheritance of Fatty Acid Content in Peanut Oil. N. C. Agriculture Research Service, v. 17, n. 12256, p. 17-21, 1990.

MEUWISSEN, T. H. E.; HAYES, B. J.; GODDARD, M. E. Prediction of total genetic value using genome-wide dense marker maps. Genetics, v. 157, n. 4, p. 1819-1829, 2001.

NEGRO, S. S.; MILLET, E. J.; MADUR, D.; BAULAND, C.; COMBES, V.; WELCKER, C.; TARDIEU, F.; CHARCOSSET, A.; NICOLAS, S. D. Genotyping-by-sequencing and SNParrays are complementary for detecting quantitative trait loci by tagging different haplotypes in association studies. BMC Plant Biology, v. 19, n. 318, p. 1-22, 2019.

PANTHEE, D. R.; PANTAlONE, V. R.; SAXTON, A. M. Modifier QTL for fatty acid composition in soybean oil. Euphytica, v. 152, p 67-73, 2006.

PÉRTILE, S. F. N.; FONSECA E SILVA, F.; SALVIAN, M.; MOURÃO, G. B. Seleção e associação genômica ampla para o melhoramento genético animal com uso do método ssGBLUP. Pesquisa Agropecuaria Brasileira, v. 51, n. 10, p. 1729-1736, 2016. DOI: 10.1590/S0100-204X2016001000004.

PHAM, A.; LEE, J.; SHANNON, J. G.; BILYEU, K. D. Mutant alleles of FAD2-1A and FAD21B combine to produce soybeans with the high oleic acid seed oil trait. BMC Plant Biology, v. 10, n. 195, p. 1-13, 2010.

PHAM, A.; LEE, J.; SHANNON, J. G.; BILYEU, K. D. A novel FAD2 - 1 A allele in a soybean plant introduction offers an alternate means to produce soybean seed oil with $85 \%$ oleic acid content. Theo Appl Gent, v. 123, p. 793-802, 2011. DOI: 10.1007/s00122-011-16273.

PRIOLLI, R. H. G.; CARVALHO, C. R. L.; BAJAY, M. M.; PINHEIRO, J. B.; VELLO, N. A. Genome analysis to identify SNPs associated with oil content and fatty acid components in soybean. Euphytica, v. 215, n. 3, p. 1-14, 2019. DOI: 10.1007/s10681-019-2378-5. 
PUTH, M. T.; NEUHÄUSER, M.; RUXTON, G. D. Effective use of Pearson's productmoment correlation coefficient. Animal Behaviour, v. 93, p. 183-189, 2014. DOI: 10.1016/j.anbehav.2014.05.003.

R CORE TEAM, 2015. R: A Language and Environment for Statistical Computing.

RESENDE, M. D. V; LOPES, P. P. S.; SILVA, R. L.; PIRES, I. E.; SILVA, R. L.; PIRES, I. E. Seleção genômica ampla (GWS) e maximização da eficiência do melhoramento genético. Pesquisa Florestal Brasileira, v. 56, p. 63-77, 2008.

SCHMUTZ, J.; CANNON, S. B; SCHLUETER, J.; MA, J.; MITROS, T.; NELSON, W.; HYTEN, D. L; SONG, Q.; THELEN, J. J; CHENG, J.; XU, D.; HELLSTEN, U.; MAY, G. D; VALLIYODAN, B.; LINDQUIST, E.; PETO, M.; GRANT, D.; SHU, S.; GOODSTEIN, D.; BARRY, K.; FUTRELL-GRIGGS, M.; ABERNATHY, B.; DU, J.; TIAN, Z.; ZHU, L.; GILL, N.; JOSHI, T.; LIBAULT, M.; SETHURAMAN, A.; ZHANG, X.; SHINOZAKI, K.; NGUYEN, H. T; WING, R. A; CREGAN, P.; SPECHT, J.; GRIMWOOD, J.; ROKHSAR, D.; STACEY, G.; SHOEMAKER, R. C; JACKSON, S. A Genome sequence of the palaeopolyploid soybean. Nature, v. 463, p. 178-183, 2010. DOI: 10.1038/nature08670.

SCHWARZ, G. Estimating the dimension of a model. The Annals of Statistics, v. 6, n. 2, p. 461-464, 1978.

SHI, Z.; BACHLEDA, N.; PHAM, A. T.; BILYEU, K.; SHANNON, G.; NGUYEN, H.; LI, Z. High-throughput and functional SNP detection assays for oleic and linolenic acids in soybean. Molecular Breeding, v. 35, n. 176, p. 1-10, 2015. DOI: 10.1007/s11032-0150368-4.

SMALLWOOD, C. J.; SAXTON, A. M.; GILLMAN, J. D.; BHANDARI, H. S.; WADL, P. A.; FALLEN, B. D.; HYTEN, D. L.; SONG, Q.; PANTALONE, V. R. Context-specific genomic selection strategies outperform phenotypic selection for soybean quantitative traits in the progeny row stage. Crop Science, v. 59, n. 1, p. 54-67, 2019. DOI: 10.2135/cropsci2018.03.0197. 
SONG, Q.; YAN, L.; QUIGLEY, C.; FICKUS, E.; WEI, H.; CHEN, L.; DONG, F.; ARAYA, S.; LIU, J.; HYTEN, D.; PANTALONE, V.; NELSON, R. L. Soybean BARCSoySNP6K: An assay for soybean genetics and breeding research. Plant Journal, v. 104, n. 3, p. 800811, 2020. DOI: 10.1111/tpj.14960.

STEWART-BROWN, B. B.; SONG, Q.; VAUGHN, J. N.; LI, Z. Genomic selection for yield and seed composition traits within an applied soybean breeding program. G3: Genes, Genomes, Genetics, v. 9, n. 7, p. 2253-2265, 2019. DOI: 10.1534/g3.118.200917.

VANRADEN, P. M. Efficient methods to compute genomic predictions. Journal of Dairy Science, v. 91, p. 4414-4423, 2008. DOI: 10.3168/jds.2007-0980.

WANG, Y.; LIN, G.; LI, C.; STOTHARD, P. Genotype Imputation Methods and Their Effects on Genomic Predictions in Cattle. Springer Science Reviews, v. 4, p. 79-98, 2016. DOI: 10.1007/s40362-017-0041-x. 
ANEXOS

Tabela 4. Médias e desvios padrão dos erros médios quadráticos de predição.

\begin{tabular}{ccccccc}
\hline & Linoleico & Linolênico & Óleo & Oleico & Palmítico & Esteárico \\
\hline 6K_BayesB & $26,29(1,76)$ & $1,31(0,05)$ & $2,78(0,10)$ & $36,40(2,47)$ & $2,55(0,12)$ & $0,17(0,00)$ \\
6K_GBLUP & $25,60(1,56)$ & $1,27(0,05)$ & $2,75(0,12)$ & $34,56(2,45)$ & $1,94(0,20)$ & $0,16(0,00)$ \\
GBS_BayesB & $32,04(1,75)$ & $1,34(0,05)$ & $2,45(0,08)$ & $47,17(2,65)$ & $2,82(0,10)$ & $0,15(0,00)$ \\
GBS_GBLUP & $31,32(1,91)$ & $1,33(0,05)$ & $2,38(0,09)$ & $44,89(2,94)$ & $2,68(0,19)$ & $0,15(0,00)$ \\
\hline Médias gerais & $28,81(1,74)$ & $1,31(0,05)$ & $2,59(0,39)$ & $40,75(2,63)$ & $2,49(0,15)$ & $0,16(0,00)$ \\
\hline
\end{tabular}

Fonte: Própria, 2021.

Tabela 5. Médias e desvios padrão das acurácias preditivas.

\begin{tabular}{ccccccc}
\hline & Linoleico & Linolênico & Óleo & Oleico & Palmítico & Esteárico \\
\hline 6K_BayesB & $0,6(0,04)$ & $0,63(0,02)$ & $0,75(0,01)$ & $0,7(0,03)$ & $0,32(0,07)$ & $0,35(0,03)$ \\
6K_GBLUP & $0,6(0,03)$ & $0,64(0,02)$ & $0,75(0,01)$ & $0,7(0,03)$ & $0,56(0,07)$ & $0,38(0,02)$ \\
GBS_BayesB & $0,44(0,05)$ & $0,62(0,02)$ & $0,79(0,01)$ & $0,54(0,04)$ & $0,14(0,07)$ & $0,44(0,02)$ \\
GBS_GBLUP & $0,47(0,05)$ & $0,61(0,02)$ & $0,79(0,01)$ & $0,57(0,04)$ & $0,32(0,07)$ & $0,44(0,02)$ \\
\hline Médias gerais & $0,53(0,04)$ & $0,62(0,02)$ & $0,77(0,01)$ & $0,63(0,03)$ & $0,33(0,07)$ & $0,40(0,02)$ \\
\hline
\end{tabular}

Fonte: Própria, 2021. 